\title{
Adopting Augmented Reality in the Age of Industrial Digitalisation
}

\author{
Tariq Masood and Johannes Egger \\ University of Cambridge
}
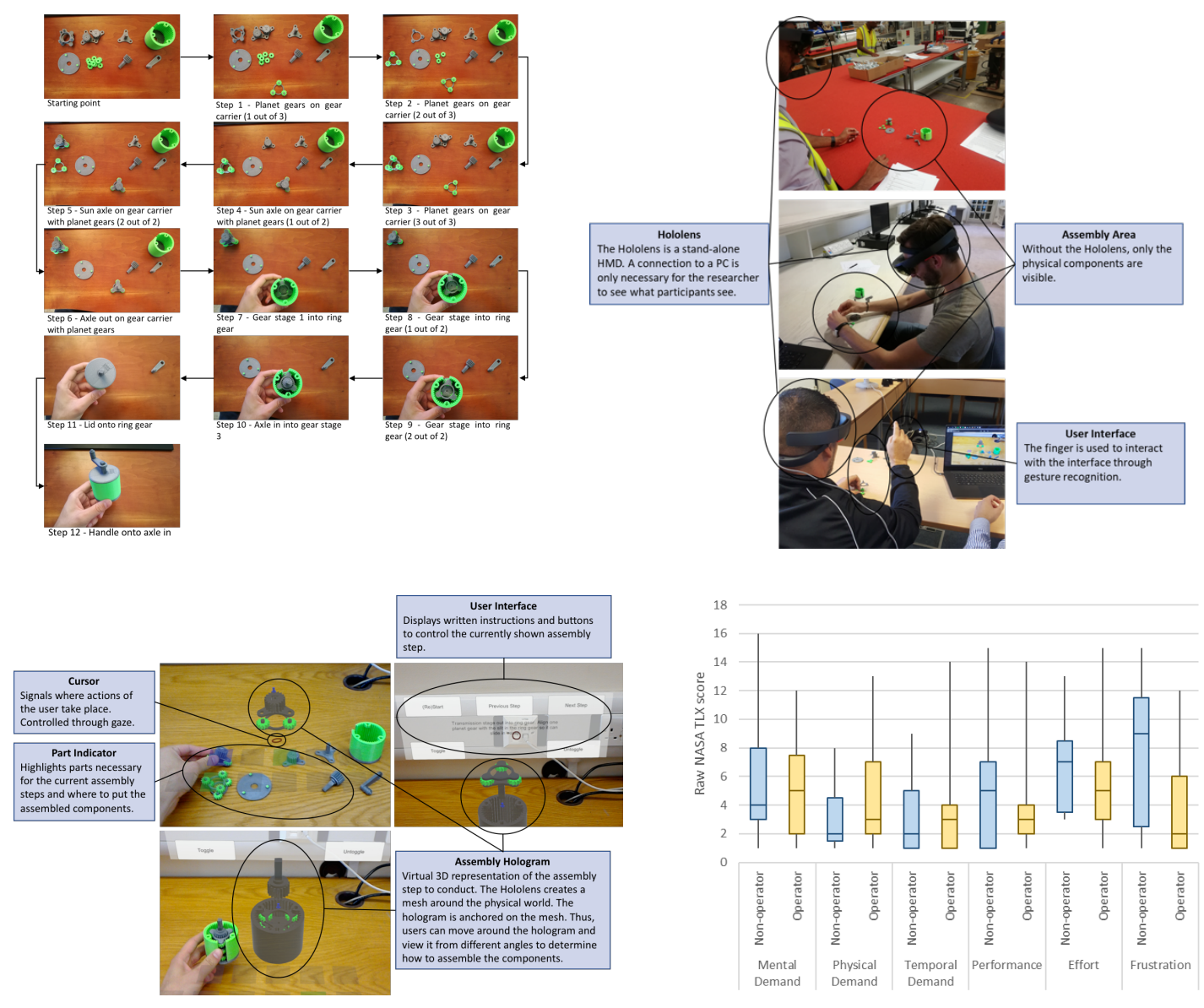

\section{Highlights}

- Industrial Augmented Reality (IAR) is a central part in the age of industrial digitalisation

- Providing guidance on which aspects industry should focus on to ensure IAR implementation success

- Achieving user acceptance, system configuration and organisational fit are key success factors

- It's challenging to have user acceptance, compatibility, hardware capability and upscaling

○ While technological aspects are important, organisational issues are more relevant for industry 


\title{
Adopting augmented reality in the age of industrial digitalisation
}

\author{
Tariq Masood $^{1,2^{*}}$ and Johannes Egger ${ }^{1}$ \\ ${ }^{1}$ Institute for Manufacturing, Department of Engineering, University of Cambridge, 17 \\ Charles Babbage Road, Cambridge CB3 OFS, UK \\ ${ }^{2}$ Engineering Design Centre, Department of Engineering, University of Cambridge, \\ Trumpington Street, Cambridge, CB2 1PZ, UK \\ *E: tm487@cam.ac.uk
}

\begin{abstract}
Industrial augmented reality (IAR) is one of the key pillars of the industrial digitalisation concepts, which connects workers with the physical world through overlaying digital information. Augmented reality (AR) market is increasing but still its adoption levels are low in industry. While companies strive to learn and adopt AR, there are chances that they fail in such endeavours due to lack of understanding key challenges and success factors in this space. This study identifies critical success factors and challenges for IAR implementation projects based on field experiments. The broadly used technology, organisation, environment (TOE) framework was used as a theoretical basis for the study, while 22 experiments were conducted for validation. It is found that, while technological aspects are of importance, organisational issues are more relevant for industry, which has not been reflected to the same extent in the literature.
\end{abstract}

\section{Keywords}

Augmented Reality, Manufacturing, Technology, Organisation, Environment, TOE, Challenges, Implementation, Critical Success Factors, Industry 4.0, Industrial Experiments, Digital

\section{List of Abbreviations}

AR Augmented Reality

AVE Average variance extracted

ES External support 
HHD hand-held device

HMD Head-mounted device

HMI Human-machine-interaction

H\&S Health and Safety

IAR Industrial Augmented Reality

IS Implementation success

LR Logistic regression

OF Organisational fit

PCA Principal component analysis

PLS Partial least square

RFID Radio frequency identification

SC System configuration

SEM Structural equation model

TAM Technology acceptance model

TC Technology compatibility

TCT Task Completion Time

THR Technology hardware readiness

TOE Technology, Organisation, Environment

UB User barriers

\section{Introduction}

The industrial digitalisation drive is making use of a number of emerging technologies. Industry 4.0 and other similar terms like Industrial Internet, or Internet 2025 are broad concepts which are built around the horizontal value network integration, the vertical integration within a value creation system, and the end-to-end engineering integration across the product lifecycle (Kagermann et al. 2013) through digital technologies.

Despite increased and intelligent automation being a vital part of those ventures, humans still play an important role in manufacturing operations (Pereira and Romero 2017; Kagermann et al. 2013). The Industry 4.0 initiative does not focus on 'dark factories' without humans, but wants to enable people to work in intelligent manufacturing environments (Kagermann et al. 2013). The augmented operator paradigm (Pereira and Romero 2017) relies on IAR to achieve that goal. IAR is classified by the European Union as one of the main technologies that will drive the smart factory development (Davies 2015) by enabling the seamless human-machine 
interactions (HMI) through visualising interactive and contextual information (Longo et al. 2017). In order to facilitate collaboration and interaction between humans and production systems based on digital data, researchers focus on utilising AR in industrial applications. However, it is unclear how to implement this technology. Hence, this research is aimed at determining success factors and challenges in implementing IAR systems.

A recent industrial survey provided guidance on which aspects industry should focus on to ensure AR implementation success with following conclusions (Masood and Egger 2019): (i) technology context and organisational fit are key success factors for the AR implementation, (ii) user barrier and external support do not significantly influence the AR implementation success, (iii) while technological aspects are important, organisational issues are more relevant for industry. This article extends the work presented in Masood and Egger (2019) by conducting 22 experiments in industry the results of which are presented here.

The rest of the article is structured as follows. The literature on IAR is reviewed, and challenges are identified as well as research questions are formulated in section 2 . Then experiment methodology is outlined in section 3. The results of the experiments are presented in section 4. After the discussion in section 5, section 6 concludes this article.

\section{Industrial Augmented Reality}

In this section, the background and challenges of IAR are explained. Based on the findings, the research gap and the research questions are defined.

\subsection{Background}

At the present time, many companies see $\mathrm{AR}$ as an important tool to provide new services related to their products (Zubizarreta et al. 2019). By providing flexible real-time information and the possibility of obtaining information hands-free IAR can offer a substantial efficiency benefit (Guo et al. 2014; Hou and Wang 2013) by decreasing the error rate (Wang et al. 2016), like picking or assembly errors and it provides easy ways to communicate with experts in maintenance tasks (Mourtzis and Vlachou et al. 2017).

IAR can be used for assembly operations, either in training (Werrlich et al. 2017; Hahn et al. 2015) or as a live guidance system for operators (Blattgerste et al. 2017; Funk et al. 2017). In logistic, 'pick-by-vision' is a prominent concept utilising IAR to indicate picking locations and quantities (Hanson et al. 2017; Renner and Pfeiffer 2017; Guo et al. 2014; Reif et al. 2009). Another area of logistics where IAR can be used are general warehouse operations 
(Stoltz et al. 2017). Additional prominent fields of applications include quality assurance (Antonelli and Astanin 2015; Segovia et al. 2015) and maintenance (Martinetti et al. 2017; Masoni et al. 2017; Mourtzis and Zogopoulos et al. 2017; Palmarini et al. 2017; Zhu et al. 2012). As soon as operators depend on or can profit from (real-time) information, IAR can be used to intuitively display this information on site.

The basic components of an AR system are the visualisation technology, a sensor system, a tracking system, a processing unit, and the user interface (Wang et al. 2016). The interaction between those components, their function, and the technologies used are shown in Figure 1.

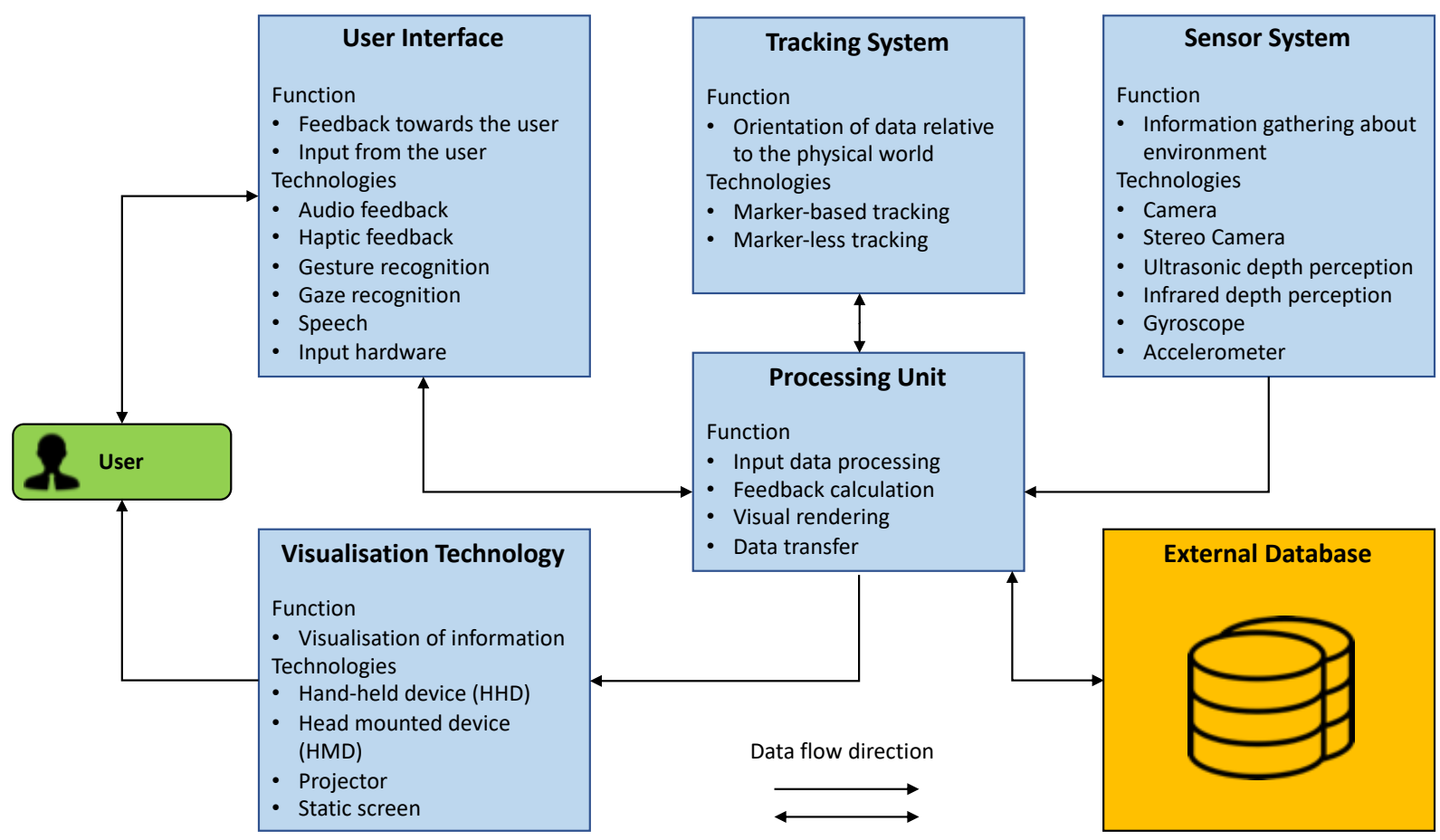

Figure 1: Components and their interaction of an AR system (based on Wang et al. 2016; Azuma 1997).

When relating the industrial application to the visualisation technology, a significant difference can be observed. Static screens or projectors are used for stationary applications, like assembly operations (Funk et al. 2017). Projection-based solutions utilise projectors to display information onto the workspace (Funk et al. 2017; Funk et al. 2016). Static screens can be used to display, e.g. interactive standard operating procedures (SOPs) (Holm et al. 2017) for the current status of the assembly and animate the next assembly step. They enable operators to move around and access and read information hands-free, speeding up operations (Syberfeldt et al. 2016). 


\subsection{Challenges}

Despite the advantages and the broad applicability, literature has identified a variety of different challenges, which are discussed in the following sections.

\subsubsection{Shop-floor and Organisational Challenges}

In general, IAR for assembly training and for assembly guidance shows promising results in laboratory environments. While the extent to which the IAR system increased the efficiency through a decreased task completion time (TCT) and a decreased error rate depends on the task complexity (Syberfeldt et al. 2016; Henderson and Feiner 2011), several studies confirm the superiority of IAR supported assembly over conventional methods, like paper-based instructions in laboratory experiments (Uva et al. 2018; Bosch et al. 2017).

However, the participants in the studies mentioned above were recruited from an academic background. It was hypothesised in literature that this selection can influence the results (Sanna et al. 2015). This was confirmed by a long-term study conducted at an automotive factory (Funk et al. 2017). While the projection-based IAR system was useful in the learning phase for untrained workers, it slowed down expert workers. Expert workers also perceived a higher cognitive workload using the IAR system as untrained workers. Hence, the experience and the background of the users themselves influence the effect of IAR solutions.

Shop-floor and organisational processes would need to be adapted in order to gain a significant advantage by supporting the task by IAR. Integration conflicts and possible disruptions have been mentioned in literature (Funk et al. 2017; Espíndola et al. 2013; Gavish et al. 2013; Porcelli et al. 2013). Porcelli et al. (2013), for example, point out, that when using IAR in maintenance, the training and work organisation of technicians needs to change. Realising the potential of IAR can only happen if organisational processes are changed.

\subsubsection{User Acceptance and Ergonomics}

In a variety of studies, the usability and ergonomics of the IAR system is a dependent variable (Kretschmer et al. 2018; Uva et al. 2018; Espíndola et al. 2013). Often, the weight of HMDs and the field of view of those devices is a point of criticism (Holm et al. 2017; Schlagowski et al. 2017; Makris et al. 2016). However, ergonomics incorporates more aspects than wearability. Murauer et al. (2018) showed that use over a work day of IAR systems can cause visual fatigue and impact concentration performance. In addition, the design of the user interface can lead to distraction or disorientation (Funk et al. 2017; Hou et al. 2013). 
No industry-wide standard has been established yet on how to design user interfaces and user interaction for augmented reality devices. Compared to touch devices, there is no common framework on how the user can give the system feedback intuitively. Different systems on gesture recognition use different hand-gestures (Saxen et al. 2017; Wang et al. 2016; Rodriguez et al. 2015).

\subsubsection{Software Capabilities}

Most of the functionality of IAR systems is related to the software. One focus area of research is the tracking technology (Blanco-Novoa et al. 2018; Kretschmer et al. 2018; Tong et al. 2016). When placing digital content in the real world, reliable tracking of the physical world is essential to provide a coherent user experience, but hard to achieve.

As the technology matures, the integration of IAR solutions into the current IT infrastructure, like product lifecycle or quality management tools is of importance (Mourtzis and Zogopoulos et al. 2017; Flatt et al. 2015; Havard et al. 2015; Serván et al. 2012). As industrial systems become digitally enabled, interfaces and content creation (authoring) need to follow certain standards (Flatt et al. 2015; Havard et al. 2015). While there is a vast number of standards available (Trappey et al. 2017), none of them is dominant yet.

\subsection{Results and Analysis of a Recent Industrial Survey}

Results and analysis of a recent industrial survey are discussed in this section (Masood and Egger 2019). This study used the technology, organisation, environment (TOE) framework as a basis for analysis (DePietro et al. 1990). Further details are reported by Masood and Egger (2019).

The metrics to analyse importance and influence concerning IAR implementation of the success factors from the qualitative part are the count and the normalised average rank. Those two metrics are then used to plot the success factors on a chart, where the x-axis represents the absolute number of how often a success factor was chosen and the $\mathrm{Y}$-axis represents the average normalised importance rank given by the respondents of the industrial survey (see Figure 2) in the interval [1,2], where 1 is the most important rank. Each dot on the chart represents one success factor. The items are classified into three distinct areas, namely high, medium, and low relevance based on their count and rank. 


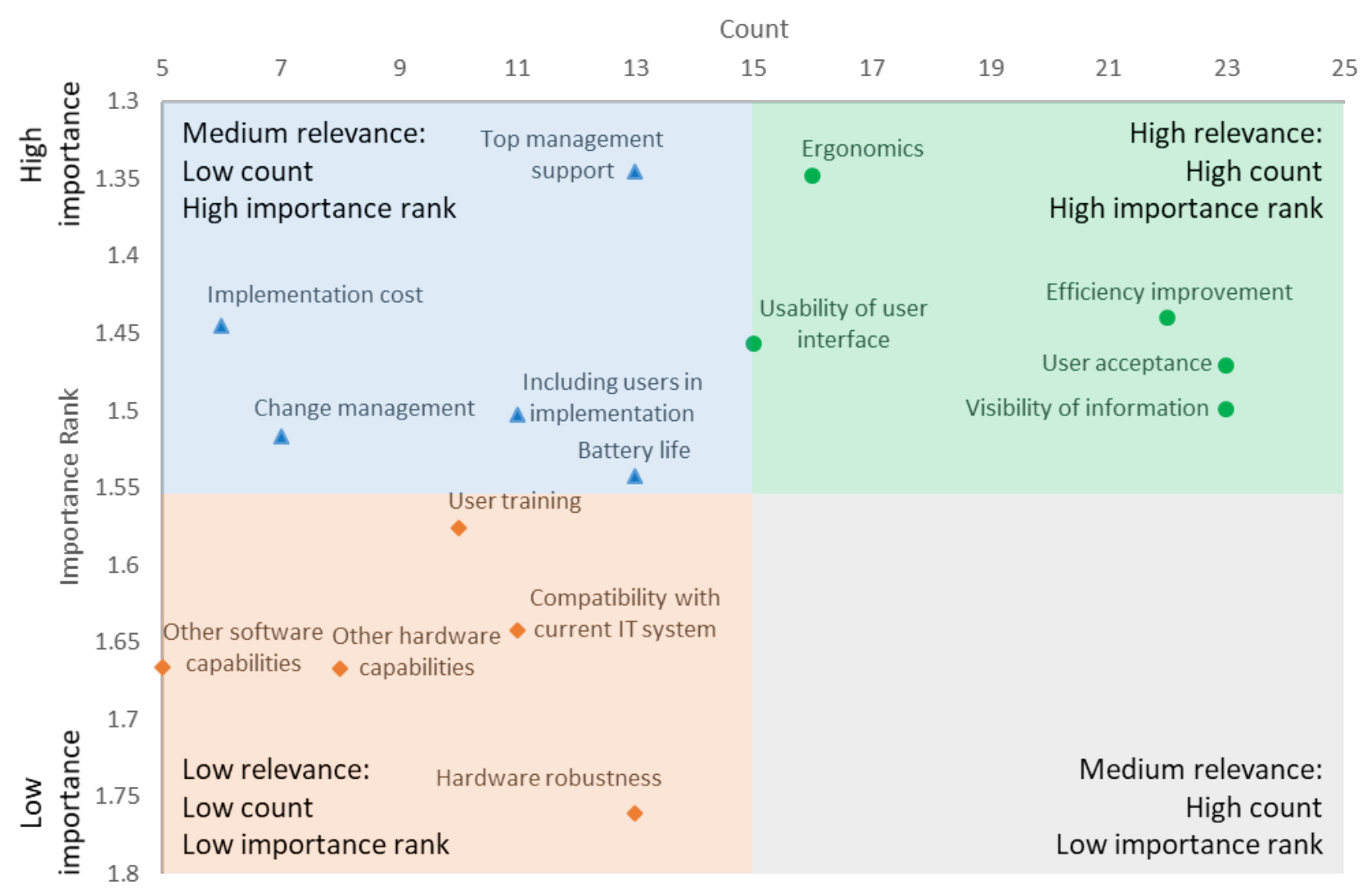

- High Relevance $\Delta$ Medium Relevance $\diamond$ Low Relevance

Figure 2: Success factors based on count and rank given by the respondents of the industrial survey (Masood and Egger 2019).

\subsection{Research Gap and Research Question}

IAR can have a significant impact on the efficiency and effectiveness of industrial operations. However, studies show that new issues arise which are not necessarily of technical nature when moving from the laboratory setting towards industrial implementation.

The compound annual growth rate of the IAR market is projected to be around $74 \%$ between 2018 and 2025 while the aggregated market of IAR will reach \$76 billion in 2025 (BIS Research 2018). This growth is likely to be sustained or accelerated by the growing maturity of IAR technology and broad variety of industrial applications. An increasing number of companies will be faced with issues arising from IAR implementation. Despite this increase in industrial diffusion of the technology, no extensive research of technology implementation has been conducted. Due to the lack of a global industry-based perspective considering the broader context of IAR implementation, the following research question is posed:

'What are the challenges and success factors for adopting augmented reality in industry?'. 


\section{Method}

This section determines a suitable research methodology, starting with the research approach (see Figure 3). 22 experiments were conducted to answer the research question.

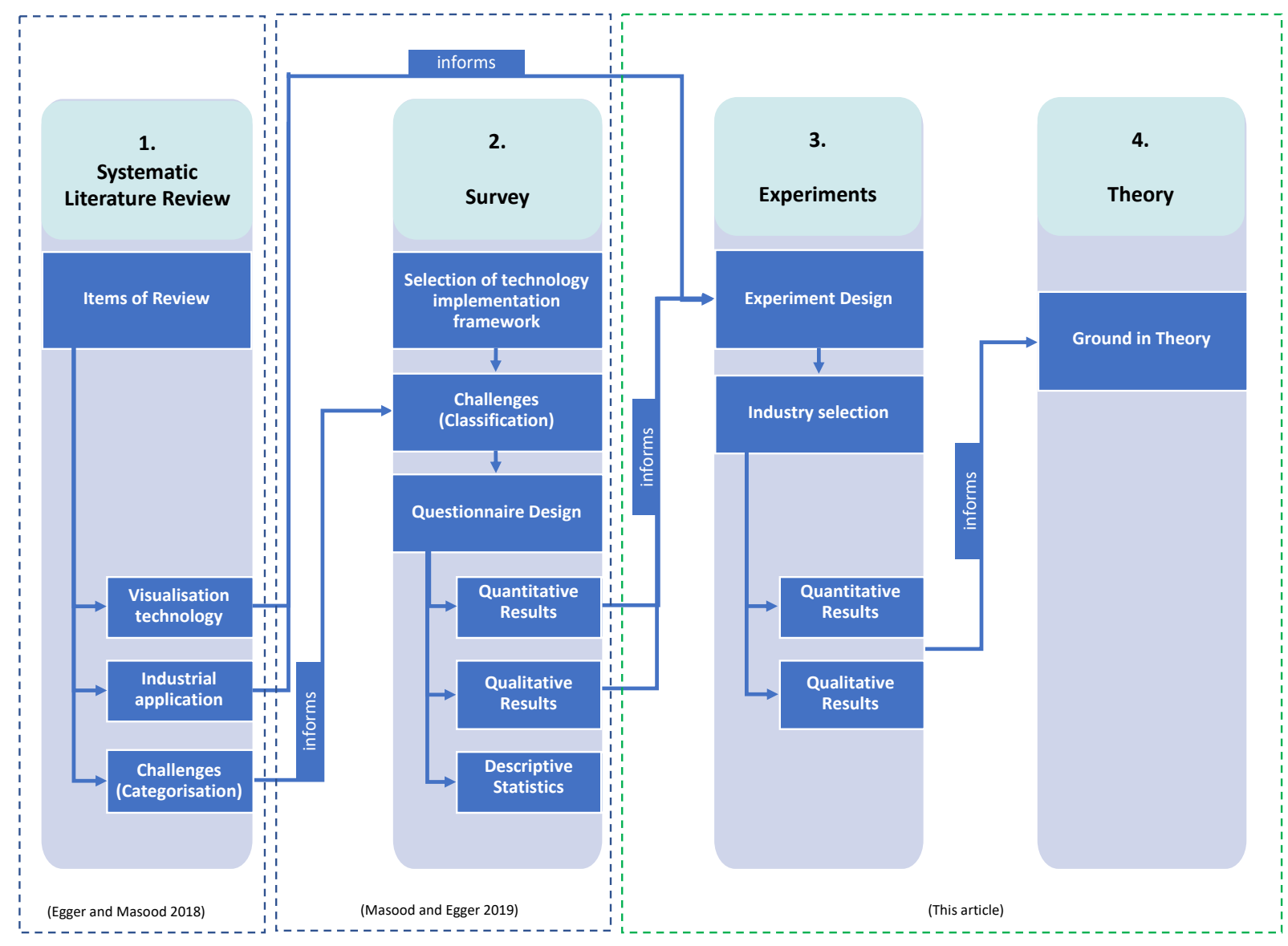

Figure 4: Overall Research approach.

This article makes use of the learnings from the systematic literature review of AR (Egger and Masood 2018) and industrial survey of AR implementation (Masood and Egger 2019) to lay foundations for the AR experiments in industry (presented in this article), which are further used to ground the theoretical knowledge.

\subsection{Experiments}

The experiment guides through an assembly task utilising an HMD (Microsoft HoloLens). An assembly application was chosen because it is prominent in the literature and in industry. However, it cannot be generalised for all IAR use cases.

\subsubsection{Research Setting}

The influence of user acceptance is controversial in the quantitative and qualitative survey results. To refine the understanding of user acceptance and how to achieve it, the study 
needed to be conducted with operators at factories. In addition, non-operator industry professionals took part as well to provide their perspectives.

Several field studies used IAR for assembly tasks (Funk et al. 2017; Syberfeldt et al. 2016; Hahn et al. 2015; Gavish et al. 2013). Gavish et al. (2013) used an HHD, which may impede the information access, as the hands-free aspect of HMDs is an important factor. Hence, an HMD was chosen for this experiment. Syberfeldt et al. (2016) did not conduct their study with operators in the field.

Hahn et al. (2015) used an HMD for assembling a printed circuit board (PCB). Due to the nature of PCBs, the use of 3D holograms is not necessary. Similarly, Funk et al. (2017) utilised in-site projection to indicate parts necessary for an assembly step. Both of the studies don't utilise 3D holograms to show the correct assembly. This experiment, however, utilises the capabilities of the HoloLens to show the correct assembly procedure as 3D hologram. As primary data from subjects is collected, ethical approval was applied for and granted by the Ethics Review Committee of the University of Cambridge Engineering Department. A participant information sheet and a consent form were used in addition to verbal information to ensure participants have sufficient knowledge about the experiment and its goals.

\subsubsection{Sample and Sample Size}

As an assembly task was chosen, one group of participants are assembly operators and field technicians. In order to validate the usability of IAR, the companies chosen have a low degree of automation.

Beckhoff automation ${ }^{1}$ is a supplier for pc-based automation equipment, used in industrial and building automation. To support their customers, Beckhoff is already looking into using IAR for maintenance tasks.

Herman Miller ${ }^{2}$ produces high-end furniture mainly for offices. Office chairs, office tables, and boundary screens are the main products produced at the site the experiment was conducted at. These products are characterised by a high degree of customisability. To some extent, certain products are one-offs. The assembly process is completely manual.

\footnotetext{
${ }^{1}$ https://beckhoff.com/

2 https://www.hermanmiller.co.uk/ 
Fluiconnecto ${ }^{3}$ assembles hydraulic hoses and connectors mainly for construction equipment manufacturers. Their assembly is organised in manufacturing cells to react flexibly to customer demands, as fluiconnecto has to deal with a low batch size and a large number of variations.

As results might differ between operators and non-operators (Sanna et al. 2015), a control group is used to identify differences between those groups. Assembly workers are recruited in the companies. Members of the control group are recruited in companies and the University of Cambridge. All of the control group members have a university degree. No incentive to participate was offered. Table 1 shows the sample description and size.

Table 1: Company background and participant classification.

\begin{tabular}{|c|c|c|c|c|c|c|c|c|}
\hline \multirow[b]{2}{*}{$\begin{array}{l}\text { Company / } \\
\text { Institution }\end{array}$} & \multirow[b]{2}{*}{ Industry } & \multirow[b]{2}{*}{ Revenue } & \multirow[b]{2}{*}{ Employees } & \multicolumn{2}{|c|}{ Operators } & \multicolumn{3}{|c|}{ Non-operators } \\
\hline & & & & $\begin{array}{l}\text { Assembly } \\
\text { Workers }\end{array}$ & $\begin{array}{c}\text { Field } \\
\text { technician }\end{array}$ & $\begin{array}{c}\text { Application } \\
\text { engineers }\end{array}$ & $\begin{array}{c}\text { (Operations) } \\
\text { Managers }\end{array}$ & Students \\
\hline $\begin{array}{l}\text { University of } \\
\text { Cambridge }\end{array}$ & University & N/A & $\begin{array}{c}11100 \\
(2015-16)\end{array}$ & 0 & 0 & 0 & 0 & 7 \\
\hline $\begin{array}{l}\text { Beckhoff } \\
\text { Automation }\end{array}$ & $\begin{array}{l}\text { Automation } \\
\text { equipment } \\
\text { supplier }\end{array}$ & $\begin{array}{l}£ 724 \\
\text { million } \\
(2017)\end{array}$ & $\begin{array}{l}3900 \\
(2017)\end{array}$ & 0 & 0 & 2 & 1 & 0 \\
\hline Herman Miller & $\begin{array}{l}\text { Furniture } \\
\text { manufacturer }\end{array}$ & $\begin{array}{l}f 2.28 \\
\text { billion } \\
(2017)\end{array}$ & $\begin{array}{l}8000 \\
(2017)\end{array}$ & 5 & 0 & 0 & 1 & 0 \\
\hline $\begin{array}{l}\text { fluiconnecto } \\
\text { (Subsidiary of the } \\
\text { Manuli Group) }\end{array}$ & $\begin{array}{l}\text { Hydraulic } \\
\text { equipment } \\
\text { manufacturer }\end{array}$ & $\begin{array}{c}\text { f121 } \\
\text { million } \\
\text { (2014) } \\
\text { (Numbers of } \\
\text { Manuli } \\
\text { Group) }\end{array}$ & $\begin{array}{c}3150 \\
(2014) \\
\text { (Numbers } \\
\text { of Manuli } \\
\text { Group) }\end{array}$ & 4 & 2 & 0 & 0 & 0 \\
\hline Total & & & & & 11 & & 11 & \\
\hline
\end{tabular}

\subsubsection{Materials}

The Microsoft HoloLens was used, which is a stand-alone device, capable of mapping the environment and placing holograms in a fixed position. Unity (Version 2017.4.1f1) was used to develop the 3D environment. Certain parts of the Holotoolkit were used in the application ${ }^{4}$. Figure 5 shows the software components of the application and how they interact based on the C4 software visualisation framework (Brown 2018) including user gaze.

\footnotetext{
${ }^{3} \mathrm{https://www.fluiconnecto.com/}$

4 The experiment code is available on Github. Necessary tools: Unity (free developers edition); Visual Studio 2018 (free developers edition): https://github.com/eggerjo/ARAssemblyGuidance
} 


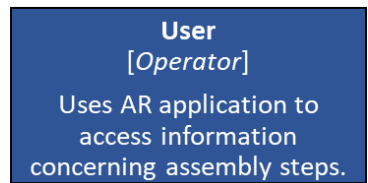

Uses

\section{Hololens Application}

[Software System]

\section{Unity Scene \\ [Container: 3D objects/C\#]}

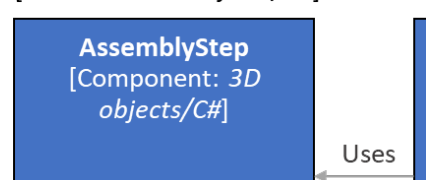

Provides the different

3D models showing

the assembly step and

indicators for the

correct part selection.

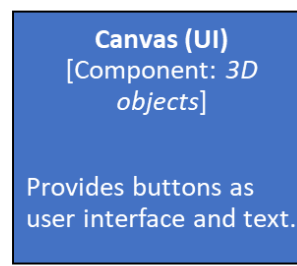

Uses

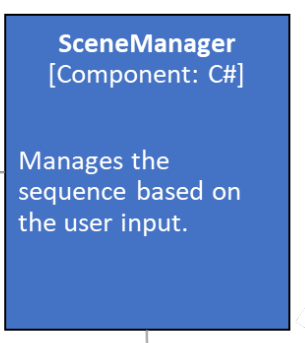

HoloToolkit

[Container: C\#]

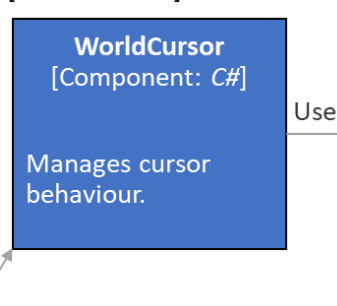

GestureManager

[Component: $\mathrm{CH}$ ]

InputManager

[Component: C\#]

Detects gestures that

interact with the user

interface.

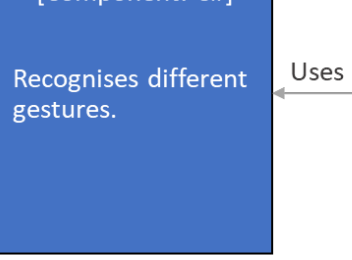

GazeManager

[Component: C\#]

Recognises gaze.

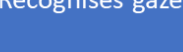

Uses

TapToPlace

[Component: $\mathrm{CH}$ ]

Enables manual

placement of the

hologram based on

the spatial map of

the environment.

Figure 5: Framework of the software system based on the C4 framework (Brown 2018).

During the experiment, participants assembled a gearbox (see Figure 6) with three planetary stages in 12 steps (see Figure 7). The assembly is based on an open source project ${ }^{5}$ and was 3D printed on a Makerbot Replicator Gen5 available at the University of Cambridge. Figure 8 depicts a screenshot of how users see the application and describe the ways of the application to show the necessary information and different stages of the assembly process and the enhancement through IAR.

\footnotetext{
${ }^{5}$ Available from: https://www.thingiverse.com/thing:25063
} 


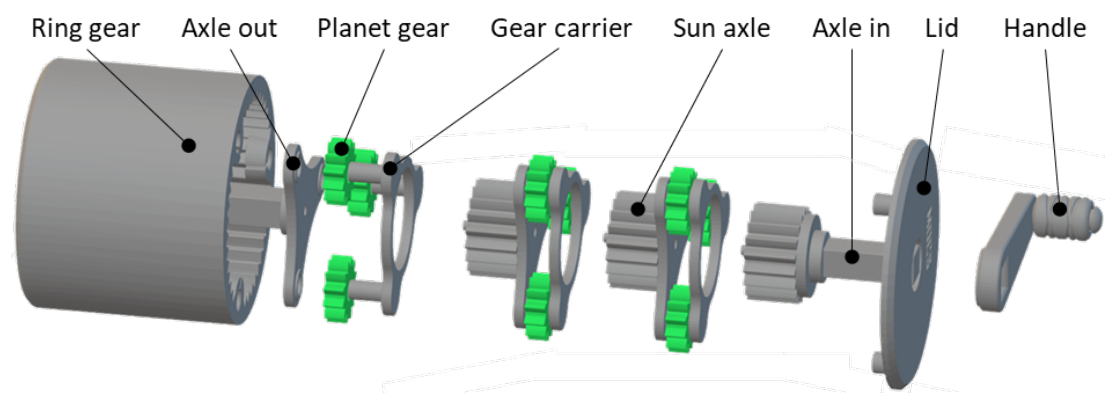

Figure 6: Exploded view of the gearbox, which is assembled in the experiment.

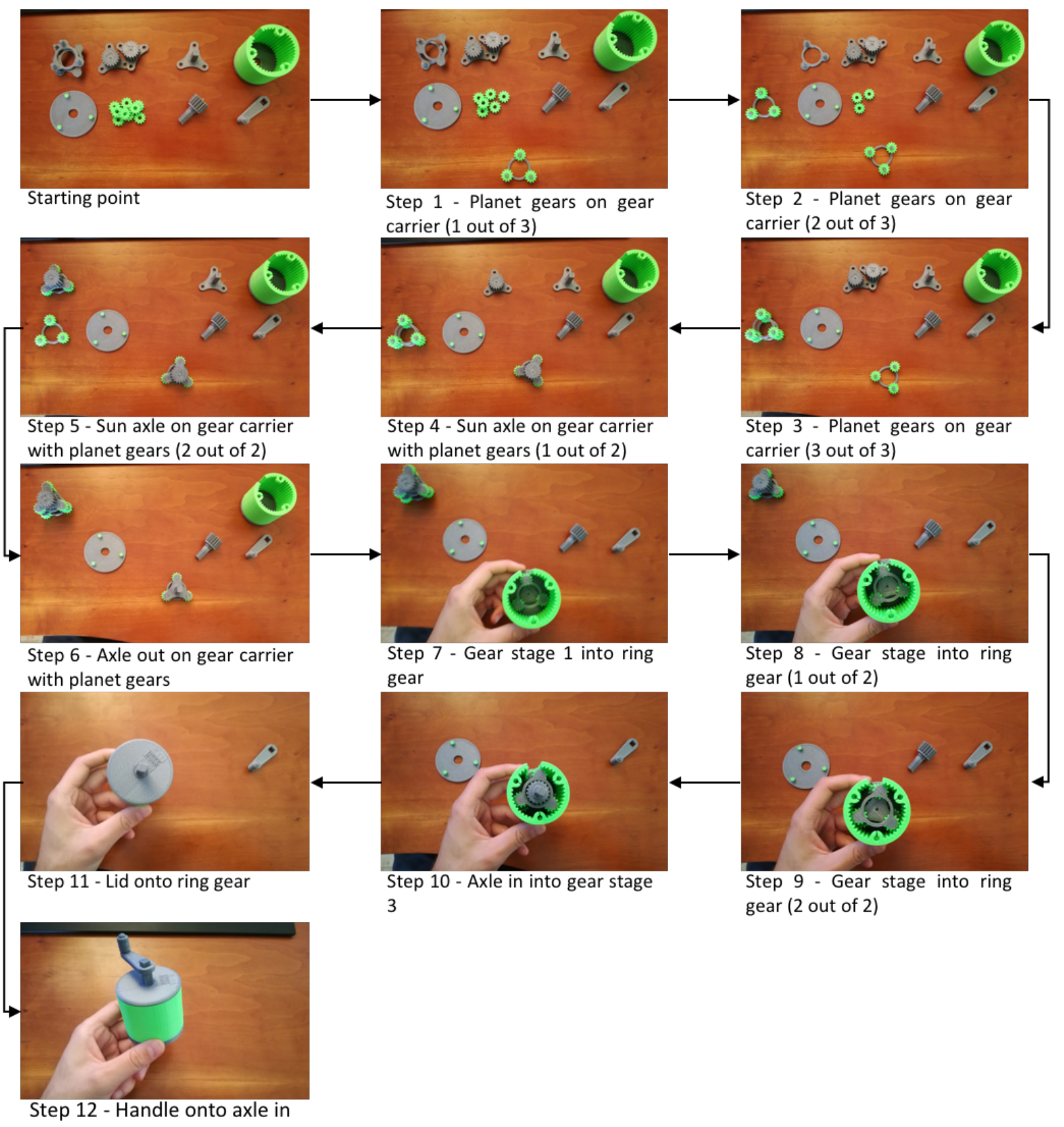

Figure 7: Gearbox assembly steps with pictures. 


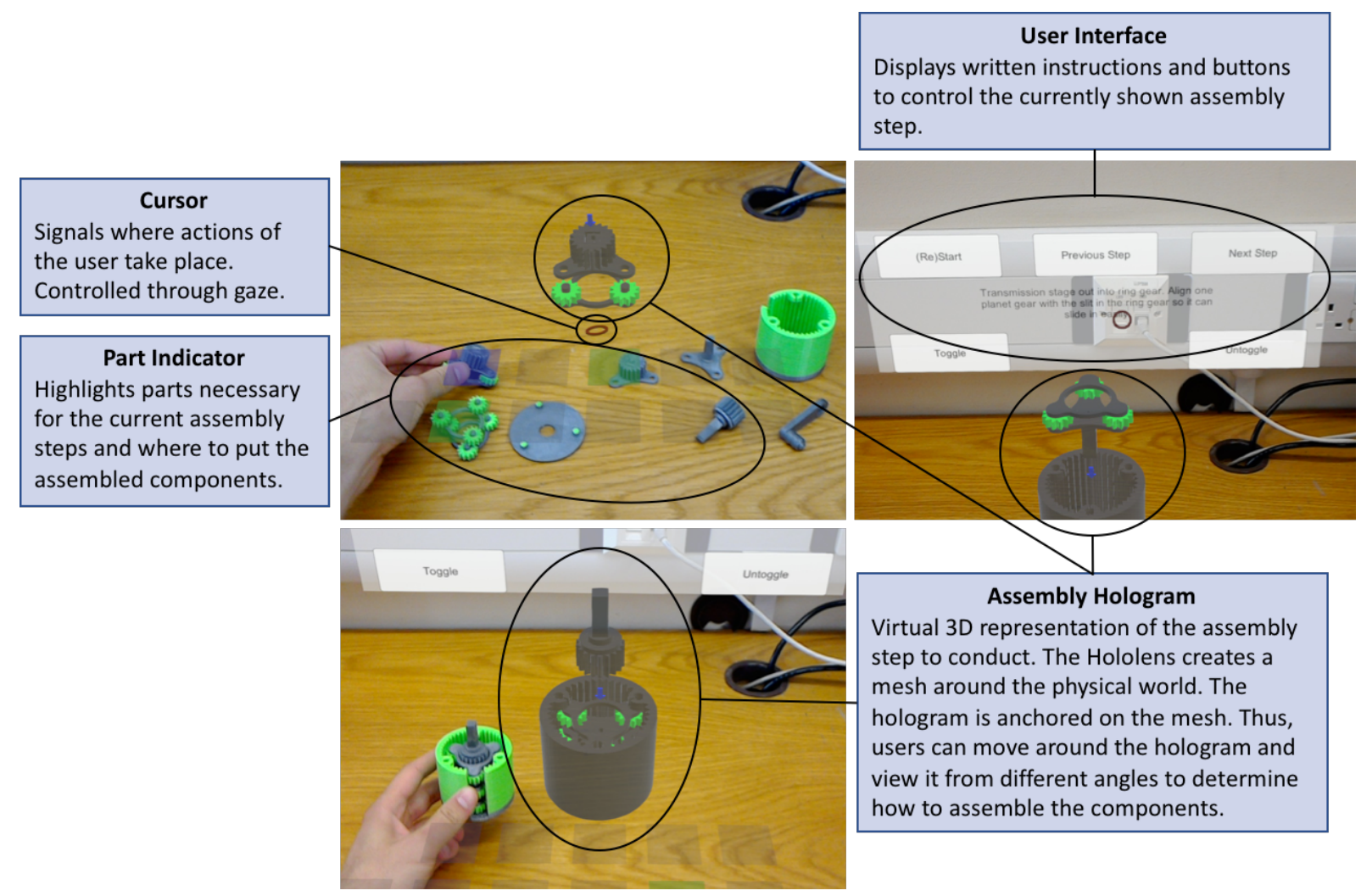

Figure 8: Impressions/user view of the HoloLens application and holograms with a description of the four main areas.

\subsubsection{Data Collection}

Data was collected through an initial questionnaire, measuring the TCT, measuring the workload with the raw NASA Task Load Index (TLX) (Hart 2016), and a feedback session in the end. In the feedback session, the questions were asked semi-structured to gain insights into the operators' perspective of IAR. Figure 9 shows the data gathering process. The TCT and the NASA TLX were aggregated into two main categories (operators and non-operators) and visualised through a boxplot. The answers to the semi-structured questions were synthesised per company according to the most relevant challenges and success factors based on the literature review and the survey. 


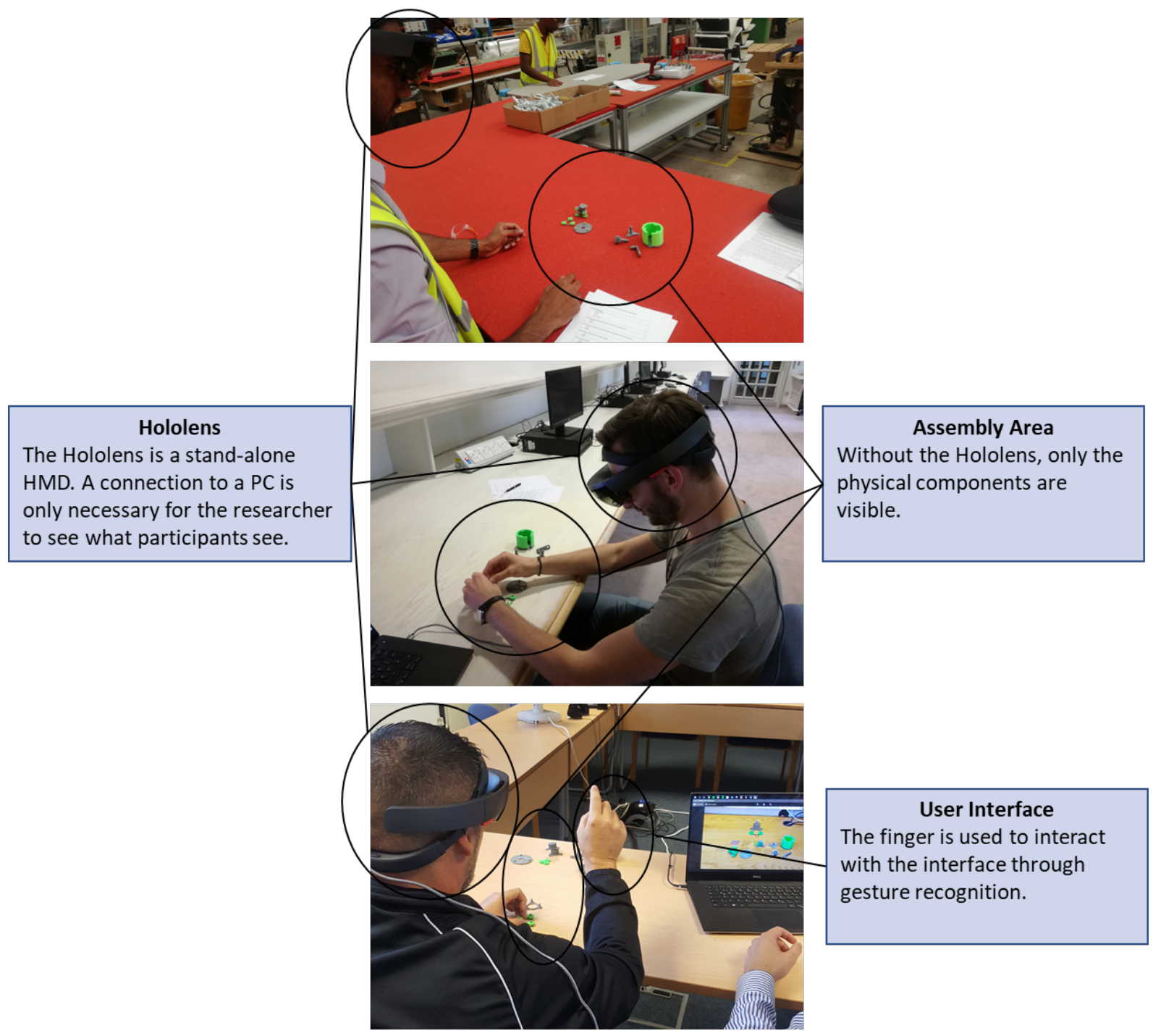

Figure 9: Impressions of the data collection.

\subsubsection{Data Analysis}

Data was analysed as follows.

\section{Results and Analysis}

This section presents the results and analysis of the 22 experiments (15 in industry, 7 in University). The results and analysis will be discussed in detail in the discussion section (see section 5).

Table 2 shows the age brackets of the experiment participants and the previous knowledge/experience with IAR. In general, more of the non-operators have heard or used IAR before the experiment. 
Table 2: Age and previous knowledge about IAR of the experiment participants.

\begin{tabular}{ccc}
\hline & Non-operators & Operators \\
\hline Age & 5 & 2 \\
below 26 & 4 & 3 \\
$26-40$ & 2 & 5 \\
$41-55$ & 0 & 1 \\
above 55 & & \\
Heard of AR before the experiment? & 10 & 6 \\
Yes & 1 & 5 \\
No & & \\
Used AR before this experiment? & 4 & 2 \\
Yes & 7 & 9 \\
No & & \\
\hline
\end{tabular}

Figure 9 shows the boxplot of the TCT. Operators take longer to finish the assembly task.

Concerning the NASA TLX, however, operators perceive the workload as lower (see Figure 0 ). Yet, the spread among both groups is high and the boxplots overlap. Hence, it cannot be conclusively stated that the perceived workload amongst operators is lower.

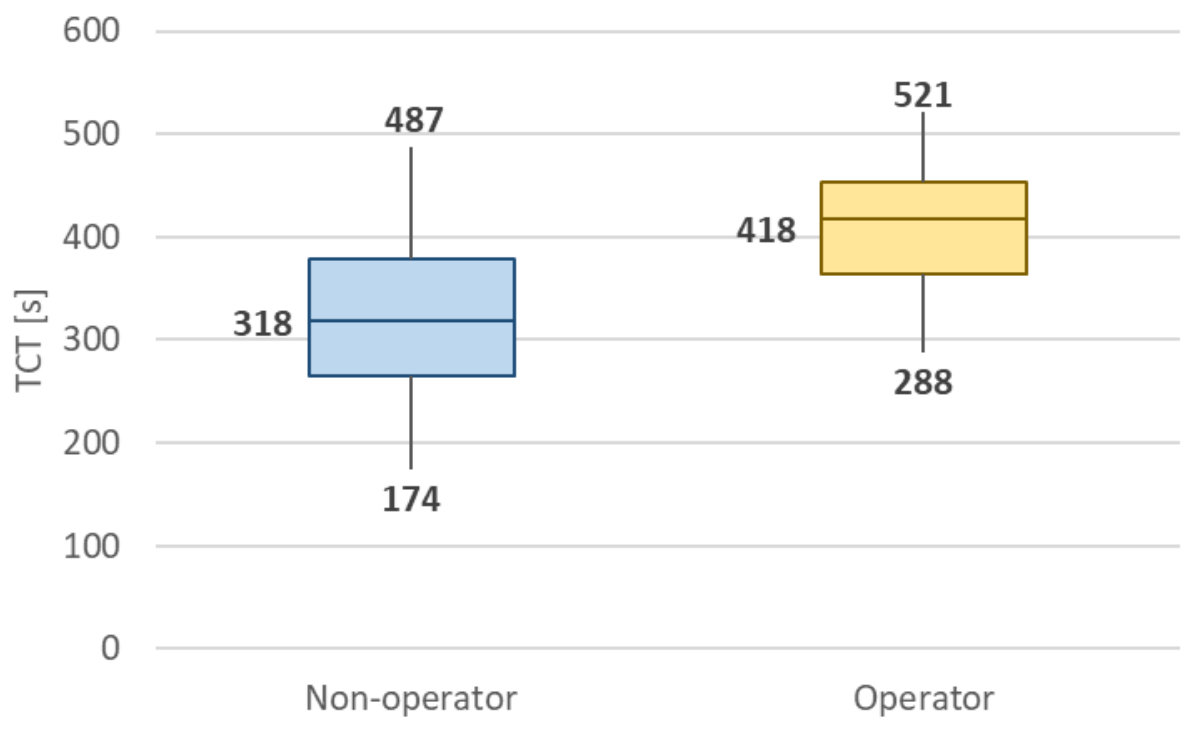

Figure 10: Boxplot of the TCT for operators and non-operators. 


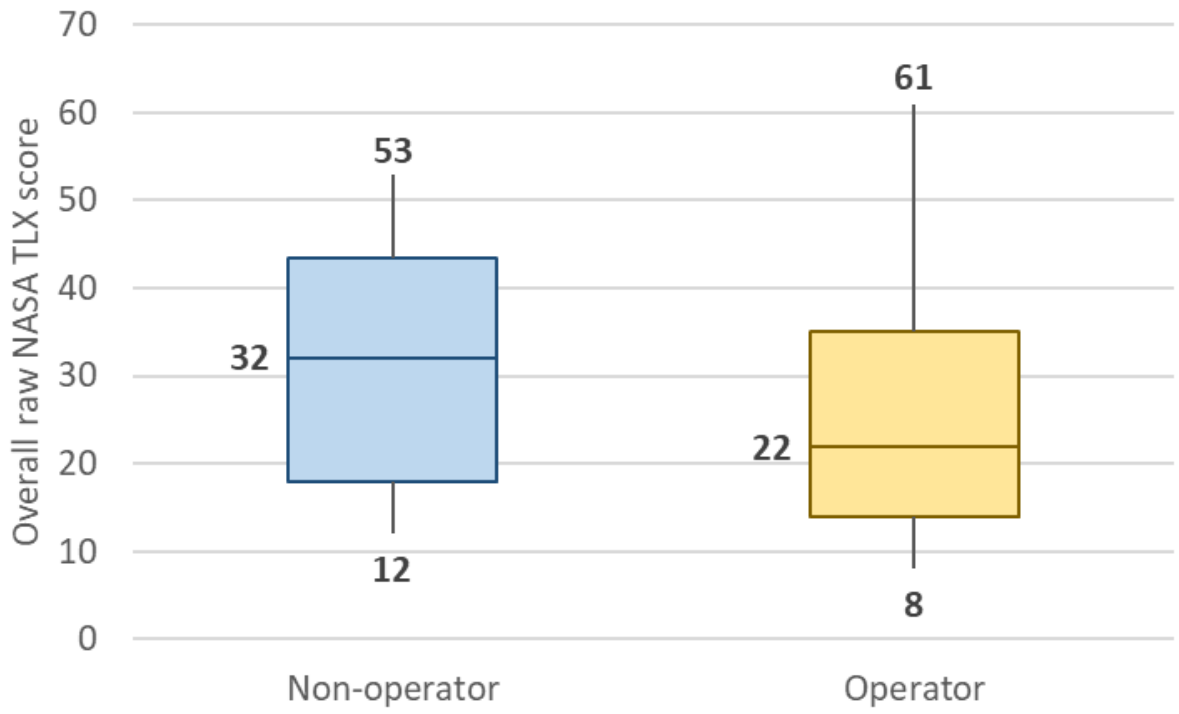

Figure 10: Boxplot of the total raw NASA TLX score for operators and non-operators.

When analysing the item scores of the NASA TLX between non-operators and operators (see Figure 11), the frustration item shows the biggest difference. In the discussion with the operators and non-operators after the assembly task, it became clear the frustration of the nonoperators stems mainly from the assembly itself. It was frustrating for non-operators to put the parts together correctly because of the tight fit of the parts. Operators did not state this fact. 


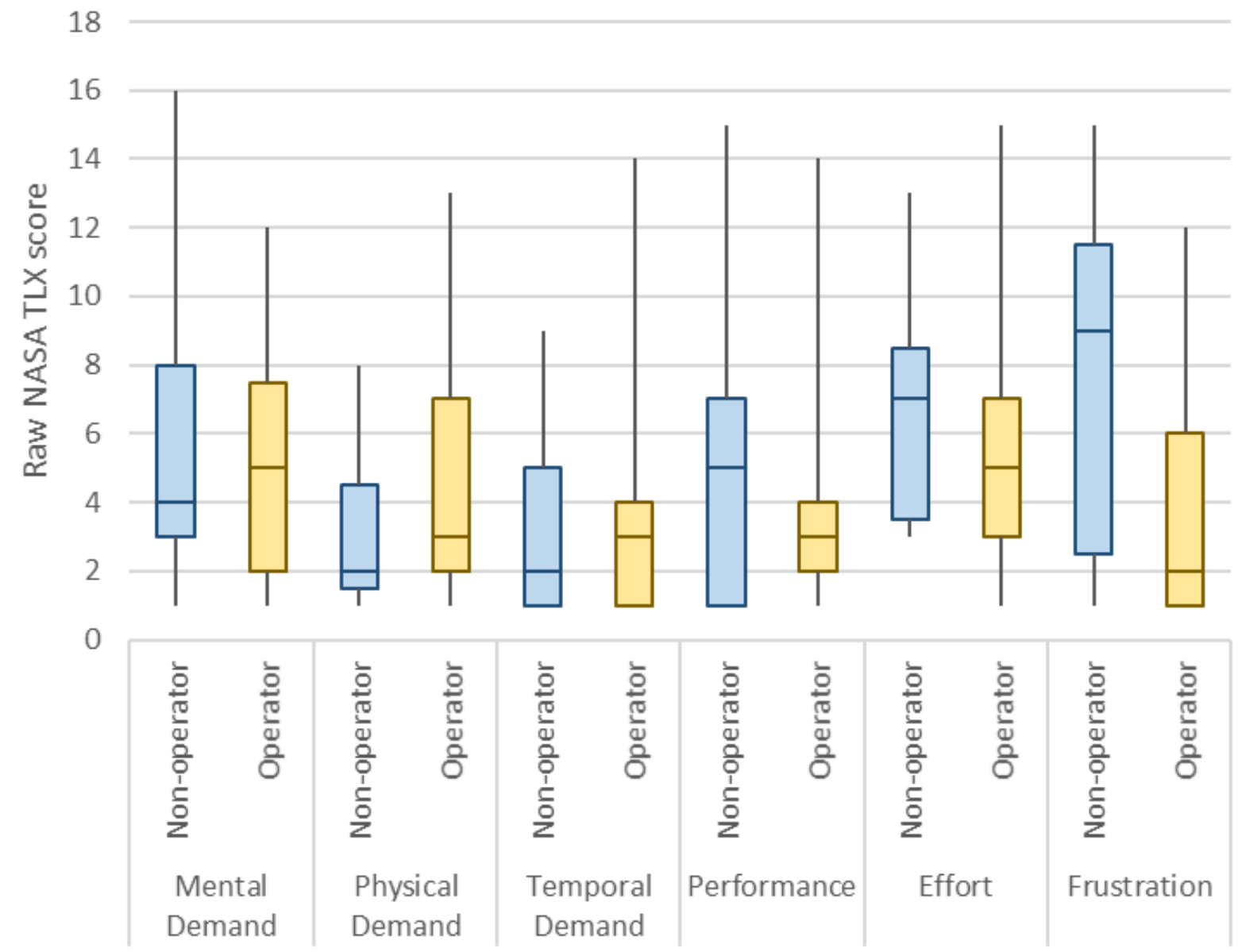

Figure 11: NASA TLX item scores.

Table 3 sums up the key-takeaways based on the three most important challenges (highest percentage) of the technology and organisation context for industry. In addition, the H\&S aspect was included, as it was specifically highlighted during the experiments. Table 4 sums up the key-takeaways according to four of the high relevance success factors. Table 4 also provides relevant use cases. 
Table 3: Challenges according to experiments feedback.

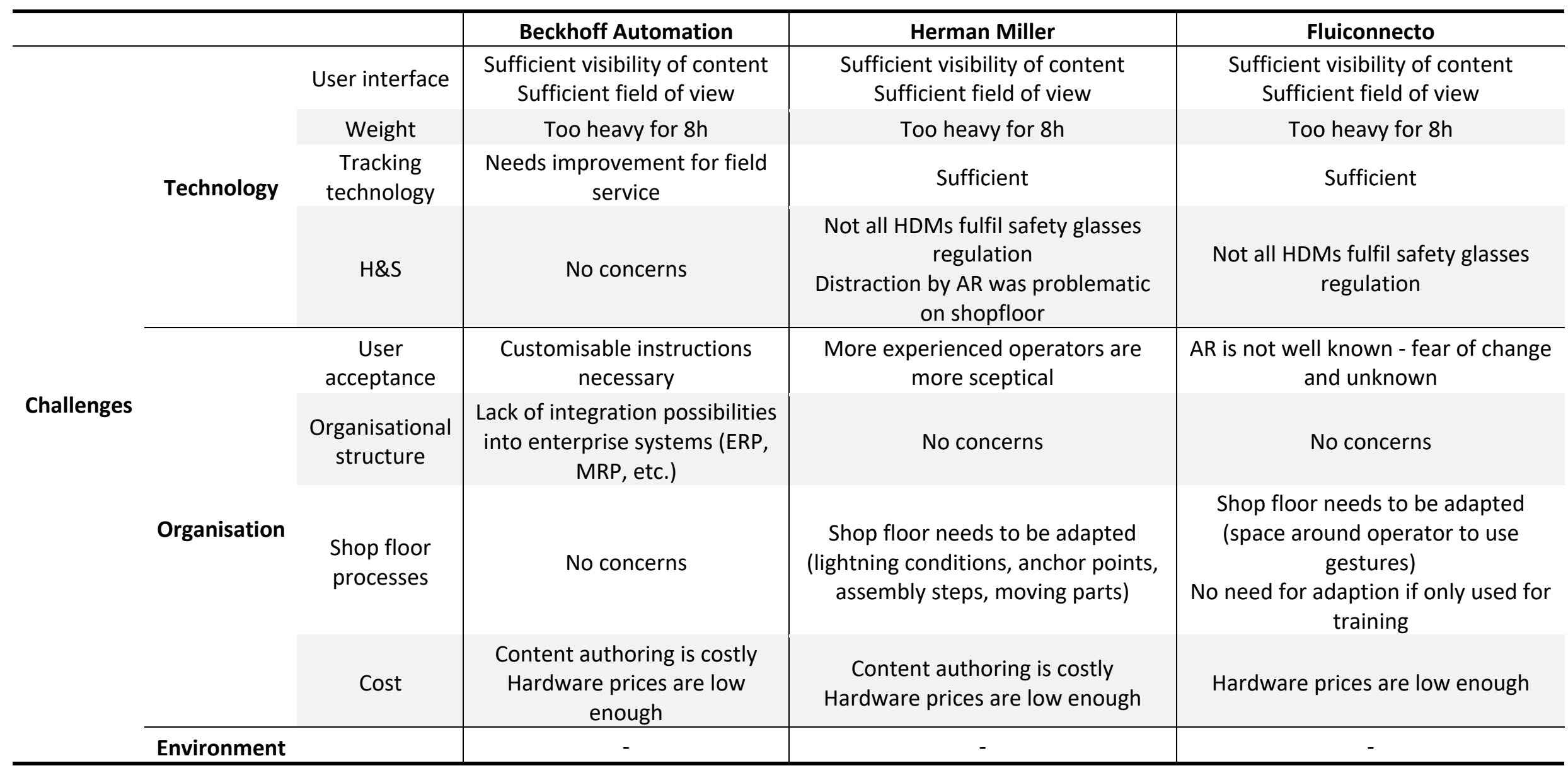


Table 4: Success factors and use cases according to experiments feedback.

\begin{tabular}{|c|c|c|c|c|}
\hline & & Beckhoff Automation & Herman Miller & Fluiconnecto \\
\hline \multirow{3}{*}{$\begin{array}{l}\text { High } \\
\text { relevance } \\
\text { success } \\
\text { factors }\end{array}$} & User acceptance & $\begin{array}{l}\text { Easy to achieve if operators benefit } \\
\text { from technology }\end{array}$ & $\begin{array}{l}\text { Sceptical operators can be convinced } \\
\text { by relevant proof of concept for them }\end{array}$ & $\begin{array}{l}\text { Users need to be educated about AR } \\
\text { early on to achieve acceptance }\end{array}$ \\
\hline & $\begin{array}{l}\text { Visibility of } \\
\text { information }\end{array}$ & Important, but already sufficient & Important, but already sufficient & Important, but already sufficient \\
\hline & Ergonomics & $\begin{array}{l}\text { Long-term pilot tests necessary with } \\
\text { different user interfaces and } \\
\text { hardware systems }\end{array}$ & Weight needs to be reduced & $\begin{array}{l}\text { Important, but already sufficient for } \\
\text { training purpose }\end{array}$ \\
\hline & Use Cases & $\begin{array}{c}\text { Field service } \\
\text { Non-repetitive assembly tasks } \\
\text { Tele-maintenance } \\
\text { Quality assurance }\end{array}$ & $\begin{array}{c}\text { Training } \\
\text { High variety/low volume assembly } \\
\text { guidance } \\
\text { Quality assurance (component } \\
\text { alignment) } \\
\text { Human-robot collaboration }\end{array}$ & $\begin{array}{c}\text { Training } \\
\text { Maintenance } \\
\text { Operating machinery }\end{array}$ \\
\hline
\end{tabular}




\section{Discussion}

In this section, the results of the experiments are discussed, compared, and related to the literature and industrial survey (Masood and Egger 2019). Then, implications for academia and industry are outlined as well as limitations of the study and possibilities for further work.

\subsection{Technology Context}

The THR is important according to the quantitative part, however not as important as the SC and the TC. This is also supported by the qualitative results, as hardware robustness and battery life are lowly ranked success factors. There are three main reasons why THR is not as important as SC and TC.

1) IAR hardware is commercially available, which indicates that a certain level of maturity has been reached. This is confirmed by the experimental feedback session (see Table 3 and Table 4), where the hardware is suitable for industrial use according to the test subjects.

2) The most significant advantage of IAR according to the survey is the effective access to information (Masood and Egger 2019). To make the information accessible on an IAR device and, thus, materialise the advantage of effective information access, the system has to be integrated into the existing IT infrastructure. Hence, the IAR system has to be (made) compatible with the current IT system (part of TC). However, compatibility with current IT system is not an important success factor according to the survey. Hence, the lack of compatibility is a challenge to overcome.

3) Lastly, the second most important advantage is the efficiency improvement through IAR. The system needs to be correctly configured to perform. Hardware and pilot tests with the users can uncover initial problems, like low visibility of the virtual content, especially as the visualisation device and technology itself has an influence on how well the IAR system performs (Renner and Pfeiffer 2017). Hence, the SC is a crucial success factor for achieving an efficiency increase. This fact aligns with the highly ranked success factor of visibility.

The second measure of SC is the system configuration according to health and safety (H\&S) standards. Not only can IAR be distracting, it can also collide with regulations governing the existing (H\&S) system (see Table 3). Especially when users wear prescription safety glasses, the use of 3D AR HMDs, like the HoloLens, is an issue. 
A challenge that emerged is the ability to scale the solution up easily. This challenge was confirmed in the feedback discussion after the experiment (see Table 3). While the cost of hardware is no issue, the ability to scale the software applications up efficiently is as system integration and content authoring are difficult (see Table 3 and Table 4). Currently, it takes programming experience to develop for every new task (for example a change in the maintenance procedure), which scales with a large-scale implementation.

\subsection{Organisation Context}

From experiments, it is evident that the user acceptance is an important challenge and a significant success factor respectively. The experiments show that introducing the technology to operators can decrease the user barriors (UB) challenge if the technology is easy to use and demonstrates capabilities useful for users. It was stated by several operators after the experiment that their reservations towards AR were alleviated through the process of introducing them to the technology and gathering their feedback (see Table 3 and Table 4).

While the NASA TLX results do not indicate a significant difference in perceived workload between operators and non-operators (see Figure 0), the TCT differs significantly (see Figure 9). Non-operators were on average 110 s faster than operators. These results contrast a longterm study where untrained workers report a lower NASA TLX and have a similar TCT (Funk et al. 2017). This could be explained by the knowledge and experience non-operators have of IAR compared to operators (see Table 2) within this research. This highlights the importance to educate and include operators early on in the implementation project to gain the expected benefits.

In general, the qualitative results indicate that most of the challenges industry is concerned with stem from an organisational point of view in contrast to academic research, which tends to have a technological focus. Yet, this is no indication that academia is not concerned with the organisation context, as the challenge categories are outlined in the literature. The survey data shows that $70 \%$ of the pilot and implementation project have started within the last three years (Masood and Egger 2019). Thus, it is possible that academic research has not sufficiently tackled the problem yet. 


\subsection{Environment Context}

The external support has no statistically significant influence on the IS. This has been observed in other studies concerned with IS (Zhu et al. 2010) or Industry 4.0 adoption (Arnold et al. 2018) as well. Several possible explanations for this issue exist.

- Companies may not use industry associations to develop and promote de-facto industry standards, as the industrial use is in its infancy and such information might be seen as proprietary.

- External support might be crucial in the adoption decision-making process itself, prior to the actual implementation stage. At this initial stage of the adoption decision, companies might not be equipped with an appropriate level of knowledge around IAR, as it is a new technology. Hence, the influence at the adoption stage concerning external support to build up the necessary knowledge base could be significant.

\subsection{Summary of Success Factors and Challenges}

To summarise the discussion section and to answer the research question, the three main success factors and the four main challenges of IAR implementation are highlighted in this section (see Figures 12-13). Due to the use of different methods, it is possible to validate the results through data triangulation. In addition, the experiments facilitated an in-depth understanding of each of the challenges and success factors.

The quantitative part of the survey was used to prioritise the challenges and success factors, which are validated through the qualitative part of the survey. Despite the fact that UB was not significantly correlated to IS, user acceptance is on top of the success factors and the challenges, as the qualitative part indicates that user acceptance is a key challenge and success factor. In addition, the qualitative part was used to differentiate between challenges and success factors and to uncover challenges not mentioned in the studies reviewed in the systematic literature review.

The feedback of the experiments enabled an in-depth understanding of the challenges and success factors (see Table 3 and Table 4). Additionally, the quantitative results of the experiments (see Figures 9-11) showed if operator-specific issues exist and how they could be alleviated.

It has to be noted that focusing on the identified challenges and success factors does not guarantee success when implementing IAR. Some factors were unveiled in the qualitative part, but it is unclear how strong their influence is. In addition, other factors related to 
different contexts might exist. Those can be relevant to IAR implementation as well and might be industry or application specific.

Figures 12-13 summarises the main success factors and challenges respectively.

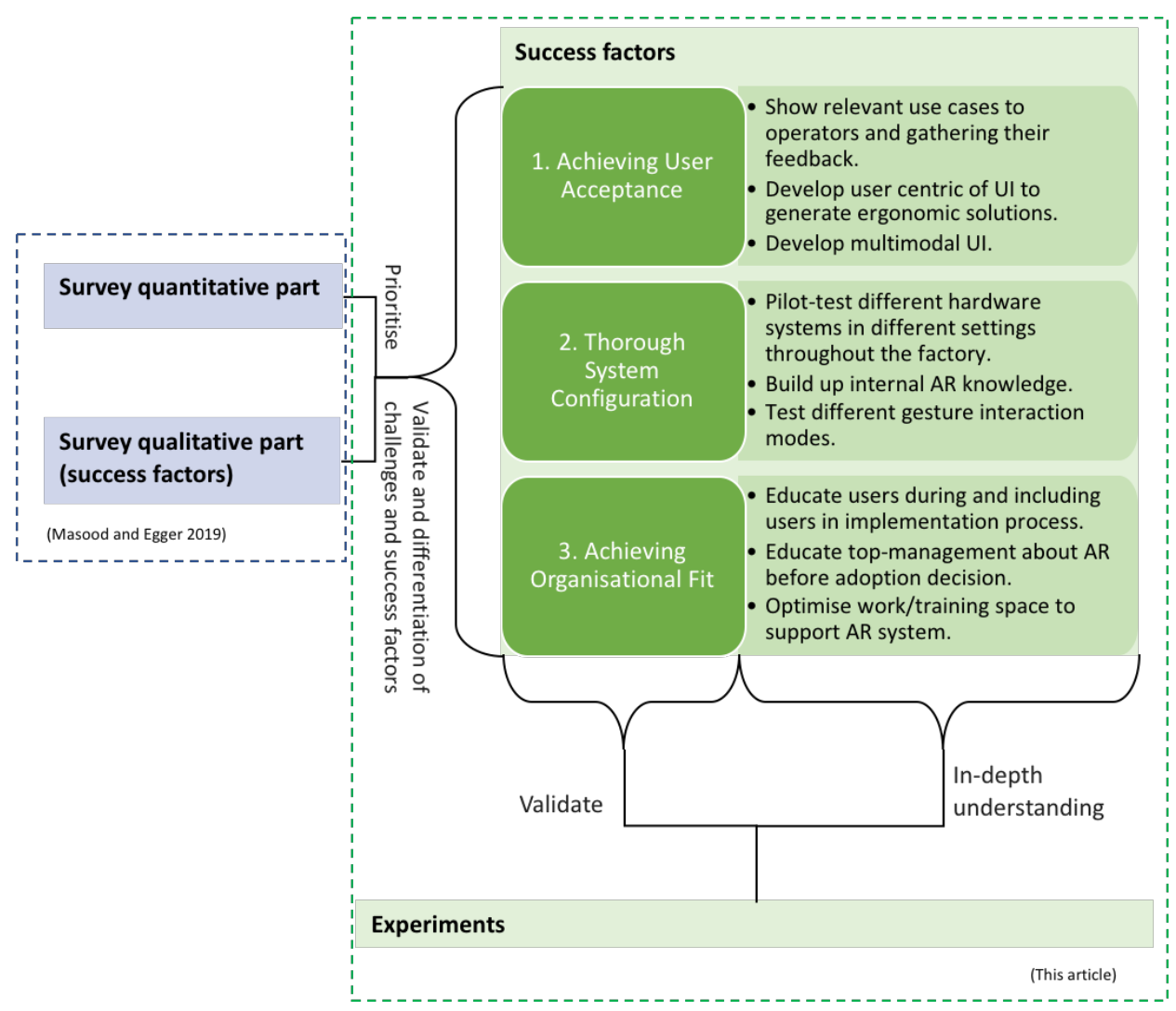

Figure 12: Main success factors for IAR implementation. 


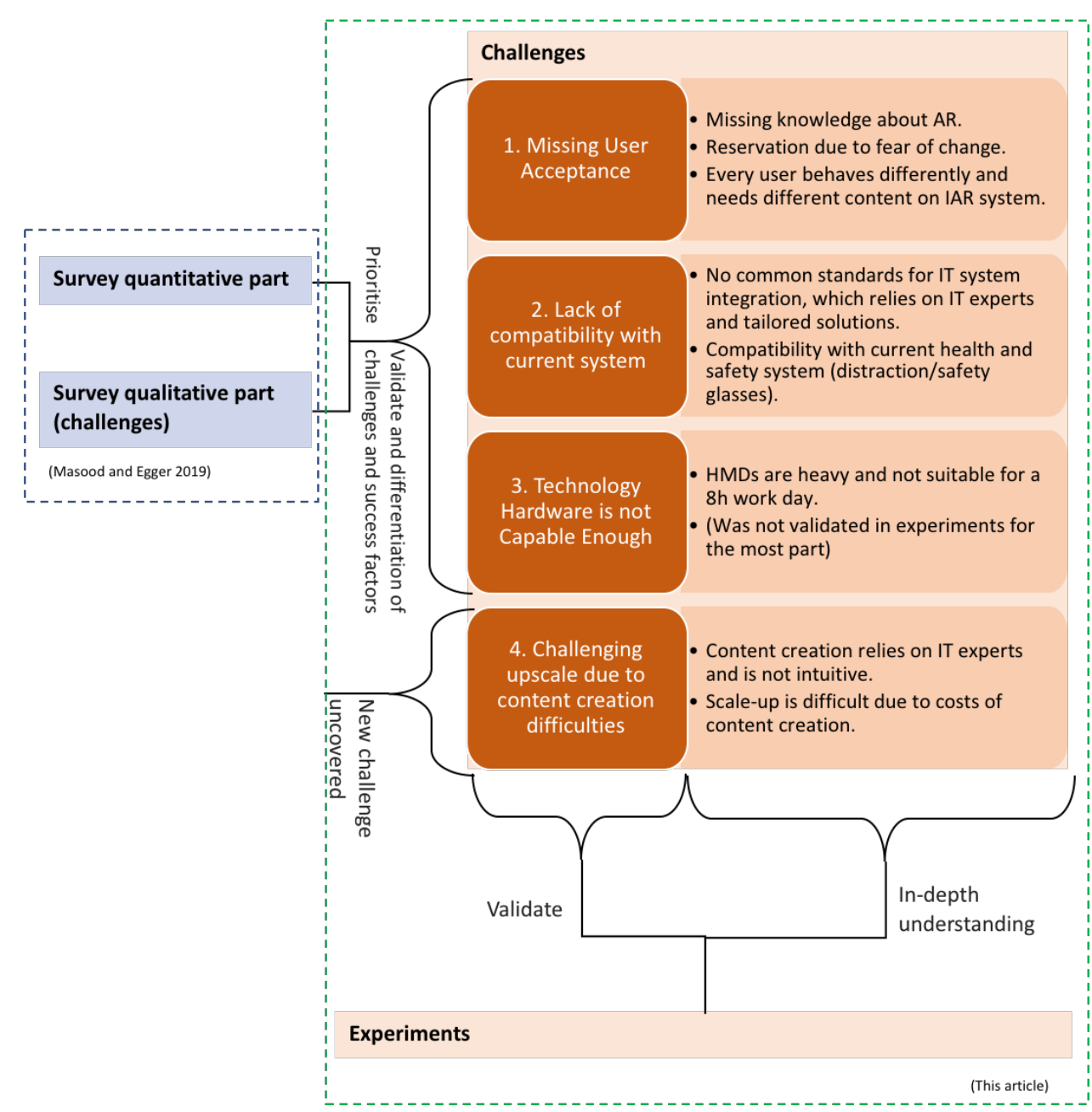

Figure 13: Main challenges of IAR implementation.

\subsection{Implications for Academia}

This study used the TOE framework to determine the effects of different factors in the IS. The quantitative part indicated factors that influence the IS and shows the empirical applicability of the TOE framework for IAR solution.

This article has contributed to the academic body of knowledge through three main aspects. First, the TOE framework has been used for a variety of Industry 4.0 related new technologies. Through the quantitative part and the qualitative categorisation according to the TOE model, this study has expanded the body of knowledge for TOE based research. Second, a quantitative, a qualitative, and an experimental perspective were utilised towards IAR implementation. Based on those three pillars, the results from industry professionals allowed to uncover and analyse challenges and success factors. Finally, the utilisation of the TOE framework grounds the findings in theory and allowed this research to frame the results in an academically recognised way. 


\subsection{Implications for Practice}

The study unveils the areas that are crucial to IAR project success. The resulting main challenges and success factors can be used as a starting point when developing an IAR system. This information acts as a guideline of crucial aspects to consider before and during the implementation phase. Hence, this article provides guidance on which aspects industry should focus on to ensure IS. As the number of implementation projects of IAR is expected to increase over the next years, a rising number of companies will be subjected to the issues presented in this article.

Academic and industrial research on AR is quite different, the former looks for new science, more robust algorithms and faster response, while industry wants solutions to their problems, to increase productivity and shorten learning curve. It is important to address how a balance can be achieved in getting the most out of AR research and applications. This article is a step forward in achieving a balance by providing insights from academic literature and linking those with industrial thinking while also providing evidence through industrial experiments.

Both academia and industry could benefit by investing more on developing AR demonstrators for various industrial sectors and applications, which can potentially increase the adoption levels of AR in industry.

\subsection{Limitation and Further Work}

IAR is a fairly new technology in industry without widespread adoption. The capabilities of the technology are still important and will be important in future, especially in support of achieving Industry 4.0 objectives, as it has not reached maturity yet. However, the technology tends to be not as important as organisational issues when implementing IAR. This shift from a technology focus to an organisational focus is not reflected in the IAR research. Due to the significant implications of the organisational fit and the compatibility of the technology towards IS, future research can focus on how to adapt processes for IAR, how to align it with the current systems, or how to ensure the operator's health and safety when using those systems.

The qualitative part of the study unveiled factors that have not been part of the quantitative study. The scalability of the IAR solution seems to be of interest for industry. Scalability can be part of a 'relative advantage' construct in the technology context for future TOE framework-based research. 
Future studies can incorporate acceptance models (like the TAM or the UTAM) into a TOEbased research project to ground these factors in theory and determine their influence. As IAR includes new hardware and can change work processes, the user side needs to be analysed in more detail.

\section{Conclusion}

The IAR is one of the major pillars of the industrial digitalisation drives. It connects workers with the digital environment. The aim of this study was to answer the research question 'What are the challenges and success factors for the implementation of industrial augmented reality?' through 22 experiments conducted in industry and university .

The contributions of this article to the academic and industrial knowledge include:

- Addition to TOE framework based research and Industry 4.0 relevant technologies. Using TOE framework, IAR challenges were identified under following classifications: Technology (user interface, weight, tracking technology, H\&S), and Organisation (user acceptance, organisational structure, shop floor processes, cost).

- Guidance for focus areas for achieving success in adopting AR in industry. High relevance IAR success factors were identified as follows: user acceptance, visibility of information, ergonomics and usability of user interface. Use cases were also identified across these factors.

- Analysis of mental, physical and temporal demands, performance, effort and frustration amongst operators and non-operators for AR adoption.

- Perceived workload amongst operators is lower as compared to non-operators for AR adoption.

While this research has shown that the technological context is the basis for a successful IAR implementation, the organisational side of the implementation is relevant for the industry as well. The user acceptance and the organisational fit are crucial success factors. As IAR might use new hardware and unfamiliar modes of interfacing with the technology, including the user in the implementation process is critical.

User acceptance is not only a success factor, but a lack of it is a serious challenge to overcome. Despite the latent variable UB not correlating significantly with the IS of IAR, the qualitative and experimental findings show the importance of users conclusively. Educating users and showing use cases relevant to them can alleviate this challenge. Additionally, the 
lack of the fragmented ecosystem leads to upscaling issues, as no easy way of content creation exists. It is the authors opinion that this challenge will diminish over time, as a dominant and easy way to create content will arise eventually.

While IAR is not ready yet for industrial deployment in some areas, it is already used in others. Companies are testing and implementing IAR solutions for different applications. While technological challenges are not a central concern for industry, the software ecosystem and the organisational integration are. However, the potential benefits of IAR shown through a broad variety of experiments incentivise to overcome those challenges.

\section{Acknowledgements}

This research was supported by the University of Cambridge and the industrial partners. The authors are most grateful to the industrial partners for their support in conducting the experiments, and reviewers and colleagues for their constructive comments.

\section{References}

Antonelli, Dario, and Sergey Astanin. "Enhancing the Quality of Manual Spot Welding through Augmented Reality Assisted Guidance.” Procedia CIRP 33 (2015):556-561.

Arnold, Christian, Johannes Veile, and Kai-Ingo Voigt. "What Drives Industry 4.0 Adoption? An Examination of Technological, Organizational, and Environmental Determinants.” In IAMOT Conference, 1-19. Birmingham 2018.

Azuma, Ronald T. "A Survey of Augmented Reality.” Presence: Teleoperators and Virtual Environments 6, 4 (1997):355-385.

Baker, Jeff. "The Technology-Organization-Environment Framework.” In Information Systems Theory. Vol. 28. Edited by Yogesh K. Dwivedi, Michael R. Wade and Scott L. Schneberger, 231-245. Integrated Series in Information Systems. New York, NY. Springer New York 2012.

Blanco-Novoa, Oscar, Tiago M. Fernandez-Carames, and Paula Fraga-Lamas et al. “A Practical Evaluation of Commercial Industrial Augmented Reality Systems in an Industry 4.0 Shipyard." IEEE Access 6 (2018):8201.

Blattgerste, Jonas, Benjamin Strenge, and Patrick Renner et al. "Comparing Conventional and Augmented Reality Instructions for Manual Assembly Tasks." In Proceedings of the 10th International Conference on Pervasive Technologies Related to Assistive Environments, 75-82. New York, NY. ACM 2017. 
Bosch, Tim, Reinier Könemann, and Hans de Cock et al. "The effects of projected versus display instructions on productivity, quality and workload in a simulated assembly task." In Proceedings of the 10th International Conference on Pervasive Technologies Related to Assistive Environments, 412-415. New York, NY. ACM 2017.

Brown, Simon. "The C4 model for software architecture." Updated August 1, 2018. Accessed August 5, 2018. http://c4model.com/.

Carmigniani, Julie, Borko Furht, and Marco Anisetti et al. "Augmented reality technologies, systems and applications." Multimedia Tools and Applications 51, 1 (2011):341-377.

Chwelos, Paul, Izak Benbasat, and Albert S. Dexter. "Research Report: Empirical Test of an EDI Adoption Model.” Information Systems Research 12, 3 (2001):304-321.

Davies, Ron. "Industry 4.0: Digitalisation for productivity and growth." European Parliamentary Research Service, 2015.

Davis, Fred D., Richard P. Bagozzi, and Paul R. Warshaw. "User Acceptance of Computer Technology: A Comparison of Two Theoretical Models.” Management Science 35, 8 (1989):982-1003.

Denyer, D., and D. Tranfield. "Producing a literature review." In The Sage handbook of organizational research methods. Edited by David A. Buchanan and Alan Bryman, 67189. Los Angeles. Sage 2009.

DePietro, Rocoo, Edith Wiarda, and Mitchell Fleischer. "The context for change: Organization, technology and environment." In The processes of technological innovation. Edited by Louis G. Tornatzky and Mitchell Fleischer, 151-175. Issues in organization and management series. Lexington Mass. Lexington Books 1990.

Dey, Arindam, Mark Billinghurst, and Robert W. Lindeman et al. “A Systematic Review of 10 Years of Augmented Reality Usability Studies: 2005 to 2014." Frontiers in Robotics and AI 37, 5 (2018):1-28.

Doshi, Ashish, Ross T. Smith, and Bruce H. Thomas et al. "Use of projector based augmented reality to improve manual spot-welding precision and accuracy for automotive manufacturing." The International Journal of Advanced Manufacturing Technology 89, 58 (2017):1279-93.

Dwivedi, Yogesh K., Boumediene Ramdani, and Peter Kawalek et al. "Predicting SMEs' adoption of enterprise systems.” Journal of Enterprise Information Management 22 (2009):10-24. 
Egger, Johannes, and Tariq Masood. "Augmented Reality in Support of Intelligent Manufacturing -A Systematic Literature Review." University of Cambridge, Cambridge, $U K, 28 / 06 / 2018$.

Espíndola, Danúbia Bueno, Luca Fumagalli, and Marco Garetti et al. “A model-based approach for data integration to improve maintenance management by mixed reality." Computers in Industry 64, 4 (2013):376-391.

Flatt, Holger, Nils Koch, and Carsten Rocker et al. "A context-aware assistance system for maintenance applications in smart factories based on augmented reality and indoor localization.” In 2015 IEEE 20th Conference on Emerging Technologies \& Factory Automation (ETFA): 8 - 11 Sept. 2015, City of Luxembourg, Luxembourg, 1-4. Piscataway, NJ. IEEE 2015.

Fornell, Claes, and David F. Larcker. "Evaluating Structural Equation Models with Unobservable Variables and Measurement Error.” Journal of Marketing Research 18, 2 (1981):39-50.

Fraga-Lamas, Paula, Tiago M. Fernandez-Carames, and Oscar Blanco-Novoa et al. "A Review on Industrial Augmented Reality Systems for the Industry 4.0 Shipyard.” IEEE Access 6 (2018):13358-13375.

Funk, Markus, Andreas Bächler, and Liane Bächler et al. "Working with Augmented Reality? A Long-Term Analysis of In-Situ Instructions at the Assembly Workplace." In Proceedings of the 10th International Conference on Pervasive Technologies Related to Assistive Environments, 222-229. New York, NY. ACM 2017.

Funk, Markus, Thomas Kosch, and Albrecht Schmidt. "Interactive worker assistance.” In roceedings of the 2016 ACM International Joint Conference on Pervasive and Ubiquitous Computing. Edited by Paul Lukowicz et al., 934-939. New York, NY. ACM 2016.

Gangwar, Hemlata, Hema Date, and R. Ramaswamy. "Understanding determinants of cloud computing adoption using an integrated TAM-TOE model." Journal of Enterprise Information Management 28, 1 (2015):107-30.

Gavish, Nirit, Teresa Gutiérrez, and Sabine Webel et al. "Evaluating virtual reality and augmented reality training for industrial maintenance and assembly tasks." Interactive Learning Environments 23, 6 (2013):778-798.

“Global Augmented Reality and Mixed Reality Market: Analysis Forecast 2018-2025.” 2018. Guo, Anhong, Thad Starner, and Shashank Raghu et al. "A comparison of order picking assisted by head-up display (HUD), cart-mounted display (CMD), light, and paper pick list." In Proceedings of the 2014 ACM International Symposium on Wearable Computers. 
Edited by Lucy Dunne, Tom Martin and Michael Beigl, 71-78. New York, NY. ACM 2014.

Hahn, Jürgen, Bernd Ludwig, and Christian Wolff. “Augmented reality-based training of the PCB assembly process." In Proceedings of the 14th International Conference on Mobile and Ubiquitous Multimedia. Edited by Clemens Holzmann and René Mayrhofer, 395-399. New York, NY. ACM 2015.

Hair, Joseph F. A primer on partial least squares structural equation modeling (PLS-SEM). Los Angeles: SAGE Publ, 2014.

Hanson, Robin, William Falkenström, and Mikael Miettinen. "Augmented reality as a means of conveying picking information in kit preparation for mixed-model assembly." Computers \& Industrial Engineering 113 (2017):570-575.

Hart, Sandra G. "Nasa-Task Load Index (NASA-TLX); 20 Years Later." Proceedings of the Human Factors and Ergonomics Society Annual Meeting 50, 9 (2016):904-908.

Havard, V., D. Baudry, and A. Louis et al. "Augmented reality maintenance demonstrator and associated modelling." In 2015 IEEE virtual reality (VR): 23 - 27 March 2015, Arles, France; [including papers from the] Workshop on Perceptual and Cognitive Issues in AR (PERCAR). Edited by Tobias Höllerer, 329-330. Piscataway, NJ. IEEE 2015.

Henderson, Steven J., and Steven K. Feiner. "Augmented reality in the psychomotor phase of a procedural task." In 10th IEEE International Symposium on Mixed and Augmented Reality (ISMAR), 2011: 26 - 29 Oct. 2011, Basel, Switzerland, 191-200. Piscataway, NJ. IEEE 2011.

Holm, Magnus, Oscar Danielsson, and Anna Syberfeldt et al. "Adaptive instructions to novice shop-floor operators using Augmented Reality." Journal of Industrial and Production Engineering 34, 5 (2017):362-374.

Hou, Lei, and Xiangyu Wang. "A study on the benefits of augmented reality in retaining working memory in assembly tasks: A focus on differences in gender." Automation in Construction 32 (2013):38-45.

Hou, Lei, Xiangyu Wang, and Leonhard Bernold et al. "Using Animated Augmented Reality to Cognitively Guide Assembly." Journal of Computing in Civil Engineering 27, 5 (2013):439-51.

Jia, Qiong, Yue Guo, and Stuart J. Barnes. "Enterprise 2.0 post-adoption: Extending the information system continuance model based on the technology-Organization-environment framework." Computers in Human Behavior 67 (2017):95-105. 
Kagermann, Hanning, Wolfgang Wahlster, and Johannes Helbig. "Umsetzungsempfehlungen für das Zukuntsprojekt Industrie 4.0: Abschlussbericht des Arbeitskreises Industrie 4.0.” BMBF, 2013. https://www.bmbf.de/files/Umsetzungsempfehlungen_Industrie4_0.pdf.

Kretschmer, V., T. Plewan, and G. Rinkenauer et al. "Smart palletisation: Cognitive ergonomics in augmented reality based palletising." In 1st International Conference on Intelligent Human Systems Integration: Integrating People and Intelligent Systems. Vol. 722, 355-360 2018.

Kumar, Karripur N., Shalini Chandra, and Supreeth Bharati et al. "Factors influencing adoption of augmented reality technology for e-commerce.” In PACIS proceedings 2016, $1-9$.

Lee, Cheon-Pyo, and Jung P. Shim. "An exploratory study of radio frequency identification (RFID) adoption in the healthcare industry." European Journal of Information Systems 16, 6 (2017):712-724.

Longo, Francesco, Letizia Nicoletti, and Antonio Padovano. "Smart operators in industry 4.0: A human-centered approach to enhance operators' capabilities and competencies within the new smart factory context." Computers \& Industrial Engineering 113 (2017):144-159.

Lowry, Paul Benjamin, and James Gaskin. "Partial Least Squares (PLS) Structural Equation Modeling (SEM) for Building and Testing Behavioral Causal Theory: When to Choose It and How to Use It." IEEE Transactions on Professional Communication 57, 2 (2014):12346.

Majewski, Maciej, and Wjciech Kacalak. "Human-Machine Speech-Based Interfaces with Augmented Reality and Interactive Systems for Controlling Mobile Cranes." In Interactive Collaborative Robotics. Edited by Andrey Ronzhin, Gerhard Rigoll and Roman Meshcheryakov, 89-98. Cham. Springer International Publishing 2016.

Makris, Sotiris, Panagiotis Karagiannis, and Spyridon Koukas et al. "Augmented reality system for operator support in human-robot collaborative assembly." CIRP Annals 65, 1 (2016):61-64.

Marangunić, Nikola, and Andrina Granić. “Technology acceptance model: A literature review from 1986 to 2013." Universal Access in the Information Society 14, 1 (2015):81-95.

Martinetti, Alberto, Mohammad Rajabalinejad, and Leo van Dongen. "Shaping the Future Maintenance Operations: Reflections on the Adoptions of Augmented Reality Through Problems and Opportunities." Procedia CIRP 59 (2017):14-17. 
Masoni, Riccardo, Francesco Ferrise, and Monica Bordegoni et al. "Supporting Remote Maintenance in Industry 4.0 through Augmented Reality." Procedia Manufacturing 11 (2017):1296-1302.

Masood, Tariq, and Johannes Egger, "Augmented reality in support of Industry 4.0 Implementation challenges and success factors". Robotics and Computer Integrated Manufacturing 58 (2019):181-195.

Masood, Tariq, Johannes Egger, and Maximilian Kern, "Future-proofing the Through-life Engineering Service Systems”. Procedia Manufacturing 16 (2018):179-186.

Milgram, Paul, Karuo Takemura, and Akira Utsumi et al. "Augmented Reality: A class of displays on the reality-virtuality continuum." Telemanipulator and Telepresence Technologies, 2351 (1994):282-2802.

Mishra, Abhay Nath, Prabhudev Konana, and Anitesh Barua. "Antecedents and Consequences of Internet Use in Procurement: An Empirical Investigation of U.S. Manufacturing Firms.” Information Systems Research 18, 1 (2007):103-120.

Mourtzis, D., V. Zogopoulos, and E. Vlachou. “Augmented Reality Application to Support Remote Maintenance as a Service in the Robotics Industry." Procedia CIRP 63 (2017):4651.

Mourtzis, Dimitris, Aikaterini Vlachou, and Vasilios Zogopoulos. "Cloud-Based Augmented Reality Remote Maintenance Through Shop-Floor Monitoring: A Product-Service System Approach.” Journal of Manufacturing Science and Engineering 139, 6 (2017):1-11.

Murauer, Nela, Nerina Pflanz, and Cecilia von Hassel. "Comparison of Scan-Mechanisms in Augmented Reality-Supported Order Picking Processes." CEUR Workshop Proceedings 2082 (2018):69-76.

National Statistical Service. "Sample Size Calculator.” Accessed July 12, 2018. http://www.nss.gov.au/nss/home.nsf/pages/Sample+size+calculator.

Oliveira, Tiago, and Maria F. Martins. "Literature Review of Information Technology Adoption Models at Firm Level." The Electronic Journal Information Systems Evaluation 14, 1 (2011):110-121.

Oliveira, Tiago, Manoj Thomas, and Mariana Espadanal. "Assessing the determinants of cloud computing adoption: An analysis of the manufacturing and services sectors." Information \& Management 51, 5 (2014):497-510. 
Palmarini, Riccardo, John Ahmet Erkoyuncu, and Rajkumar Roy. "An Innovative Process to Select Augmented Reality (AR) Technology for Maintenance.” Procedia CIRP 59 (2017):23-28.

Park, Hyung M., Seok H. Lee, and Jong S. Choi. "Wearable Augmented Reality System using Gaze Interaction." In 7th IEEE/ACM International Symposium on Mixed and Augmented Reality, 2008: ISMAR 2008; Sept. 15 - 18, 2008, Cambridge, UK. Edited by Mark A. Livingston, 175-176. Piscataway, NJ. IEEE Service Center 2008.

Pereira, A. C., and F. Romero. "A review of the meanings and the implications of the Industry 4.0 concept." Procedia Manufacturing 13 (2017):1206-1214.

Porcelli, Isabella, Mario Rapaccini, and Danúbia B. Espíndola et al. "Technical and Organizational Issues about the Introduction of Augmented Reality in Maintenance and Technical Assistance Services.” IFAC Proceedings Volumes 46, 7 (2013):257-262.

Premkumar, G. "A Meta-Analysis of Research on Information Technology Implementation in Small Business." Journal of Organizational Computing and Electronic Commerce 13, 2 (2003):91-121.

Rashid, Asif, Tariq Masood, John A. Erkoyuncu et al., "Enterprise systems' life cycle in pursuit of resilient smart factory for emerging aircraft industry: A synthesis of Critical Success Factors'(CSFs), theory, knowledge gaps, and implications". Enterprise Information Systems 39 (2017) 1-41.

Real, Joao, and Luis Marcelino. “Augmented Reality Systems for Inventorying.” In 6th Iberian Conference on Information Systems and Technologies (CISTI), 2011: 15 - 18 June 2011, Chaves, Portugal; [including workshop papers]. Edited by Álvaro Rocha, 1-9. Piscataway, NJ. IEEE 2011.

Reif, Rupert, Willibald A. Guenther, and Bjoern Schwerdtfeger et al. "Pick-by-vision comes of Age: Evaluation of an augmented reality supported picking system in real storage environment." In Proceedings of the 6th International Conference on Computer Graphics, Virtual Reality, Visualisation and Interaction. Edited by Alexandre Hardy et al., 23-32. New York, NY. ACM 2009.

Renner, Patrick, and Thies Pfeiffer. "Augmented Reality Assistance in the Central Field-ofView Outperforms Peripheral Displays for Order Picking: Results from a Virtual Reality Simulation Study.” In 2017 IEEE International Symposium on Mixed and Augmented Reality (ISMAR-Adjunct), 176-181 2017. 
Rodriguez, Leonardo, Fabian Quint, and Dominic Gorecky et al. "Developing a Mixed Reality Assistance System Based on Projection Mapping Technology for Manual Operations at Assembly Workstations.” Procedia Computer Science 75 (2015):327-333.

Rogers, Everett M. Diffusion of innovations. 4. ed. New York, NY u. a.: Free Press, 1995. http://www.loc.gov/catdir/description/simon033/94024947.html.

Sanna, A., F. Manuri, and F. Lamberti et al. "Using handheld devices to sup port augmented reality-based maintenance and assembly tasks." In IEEE International Conference on Consumer Electronics (ICCE), 2015: 9 - 12 Jan. 2015, Las Vegas, NV, USA, 178-179. Piscataway, NJ. IEEE 2015.

Sarstedt, Marko, and Erik Mooi. A Concise Guide to Market Research: The Process, Data, and Methods Using IBM SPSS Statistics. 2nd ed. 2014. Springer Texts in Business and Economics. 2014. http://dx.doi.org/10.1007/978-3-642-53965-7.

Saunders, Mark, Philip Lewis, and Adrian Thornhill. Research methods for business student: fifth Edition. 5 vols. Harlow: Pearson Education, 2009.

Saxen, Frerk, Anne Köpsel, and Simon Adler et al. "Investigation of an Augmented Realitybased Machine Operator Assistance-System.” In Companion technology: A paradigm shift in human-technology interaction. Edited by Susanne Biundo and Andreas Wendemuth, 471-483. Cognitive technologies. Cham, Switzerland. Springer 2017.

Schlagowski, R., L. Merkel, and C. Meitinger. "Design of an assistant system for industrial maintenance tasks and implementation of a prototype using augmented reality.” In 2017 IEEE International Conference on Industrial Engineering \& Engineering Management: IEEE IEEM2017 10-13 Dec, Singapore, 294-298. Piscataway, NJ. IEEE 2017.

Segovia, Daniel, Miguel Mendoza, and Eloy Mendoza et al. “Augmented Reality as a Tool for Production and Quality Monitoring.” Procedia Computer Science 75 (2015):291-300.

Serván, J., F. Mas, and J. L. Menéndez et al. “Assembly Work Instruction Deployment Using Augmented Reality.” Key Engineering Materials 502 (2012):25-30.

Stoltz, Marie-Hélène, Vaggelis Giannikas, and Duncan McFarlane et al. “Augmented Reality in Warehouse Operations: Opportunities and Barriers." IFAC-PapersOnLine 50, 1 (2017):12979-12984.

Sun, Shiwei, Casey G. Cegielski, and Lin Jia et al. "Understanding the Factors Affecting the Organizational Adoption of Big Data.” Journal of Computer Information Systems 58, 3 (2016):193-203. 
Sutherland, Ivan E. "A head-mounted three dimensional display." In Proceedings of the December 9-11, 1968, fall joint computer conference, part I on - AFIPS '68 (Fall, part I). Edited by Unknown, 757-764. New York, New York, USA. ACM Press 1968.

Syberfeldt, Anna, Oscar Danielsson, and Patrik Gustavsson. “Augmented Reality Smart Glasses in the Smart Factory: Product Evaluation Guidelines and Review of Available Products." IEEE Access 5 (2017):9118-9130.

Syberfeldt, Anna, Magnus Holm, and Oscar Danielsson et al. "Support Systems on the Industrial Shop-floors of the Future - Operators' Perspective on Augmented Reality." Procedia CIRP 44 (2016):108-13.

Tabachnick, Barbara G., and Linda S. Fidell. Using multivariate statistics. 6. ed. Boston: Pearson Education, 2013.

Tong, Yanfeng, Yongtian Wang, and Jing Chen et al. "A small scene assistant maintenance system based on optical see-through augmented reality." In the 15th ACM SIGGRAPH Conference. Edited by Yiyu Cai and Daniel Thalmann, 155-158 2016.

Tornatzky, Louis G. and Mitchell Fleischer, eds. The processes of technological innovation. Issues in organization and management series. Lexington Mass.: Lexington Books, 1990. Trappey, Amy J.C., Charles V. Trappey, and Usharani Hareesh Govindarajan et al. "A review of essential standards and patent landscapes for the Internet of Things: A key enabler for Industry 4.0.” Advanced Engineering Informatics 33 (2017):208-229.

Uva, Antonio E., Michele Gattullo, and Vito M. Manghisi et al. "Evaluating the effectiveness of spatial augmented reality in smart manufacturing: A solution for manual working stations." The International Journal of Advanced Manufacturing Technology 94, 1-4 (2018):509-521.

Venkatesh, Viswanath, Michael G. Morris, and Gordon B. Davis et al. "User Acceptance of Information Technology: Toward a Unified View." MIS Quarterly 27, 3 (2003):425-478.

Voorhees, Clay M., Michael K. Brady, and Roger Calantone et al. "Discriminant validity testing in marketing: An analysis, causes for concern, and proposed remedies." Journal of the Academy of Marketing Science 44, 1 (2016):119-134.

Wang, X., S. K. Ong, and A. Y. C. Nee. "A comprehensive survey of augmented reality assembly research." Advances in Manufacturing 4, 1 (2016):1-22.

Wang, X., S. K. Ong, and A.Y.C. Nee. "Multi-modal augmented-reality assembly guidance based on bare-hand interface." Advanced Engineering Informatics 30, 3 (2016):406-421.

Wang, Yue, Shusheng Zhang, and Sen Yang et al. "Mechanical assembly assistance using marker-less augmented reality system.” Assembly Automation 38, 1 (2018):77-87. 
Wang, Yu-Min, Yi-Shun Wang, and Yong-Fu Yang. "Understanding the determinants of RFID adoption in the manufacturing industry." Technological Forecasting and Social Change 77, 5 (2010):803-815.

Werrlich, Stefan, Kai Nitsche, and Gunther Notni. "Demand Analysis for an Augmented

Reality based Assembly Training." In Proceedings of the 10th International Conference on Pervasive Technologies Related to Assistive Environments, 416-422. New York, NY. ACM 2017.

Wolfartsberger, Josef, Jan Zenisek, and Mathias Silmbroth et al. "Towards an Augmented Reality and Sensor-Based Assistive System for Assembly Tasks." In Proceedings of the 10th International Conference on Pervasive Technologies Related to Assistive Environments, 230-231. New York, NY. ACM 2017.

Wu, Li-Chen, I-Chen Lin, and Ming-Han Tsai. “Augmented reality instruction for object assembly based on markerless tracking." In the 20th ACM SIGGRAPH Symposium. Edited by Chris Wyman and Cem Yuksel, 95-102 2016.

Yeh, Ching-Chiang, and Yi-Fan Chen. "Critical success factors for adoption of 3D printing." Technological Forecasting and Social Change 132 (2018):209-216.

Zhou, ZhiYing, Adrian David Cheok, and Yan Qiu et al. "The Role of 3-D Sound in Human Reaction and Performance in Augmented Reality Environments." IEEE Transactions on Systems, Man, and Cybernetics - Part A: Systems and Humans 37, 2 (2007):262-272.

Zhu, J., S. K. Ong, and A. Y. C. Nee. "An authorable context-aware augmented reality system to assist the maintenance technicians." The International Journal of Advanced Manufacturing Technology 45 (2012):1699-1714.

Zhu, Kevin, and Kenneth L. Kraemer. "Post-Adoption Variations in Usage and Value of EBusiness by Organizations: Cross-Country Evidence from the Retail Industry." Information Systems Research 16, 1 (2005):61-84.

Zhu, Kevin, Kenneth L. Kraemer, and Sean Xu. "The Process of Innovation Assimilation by Firms in Different Countries: A Technology Diffusion Perspective on E-Business.” Management Science 52, 10 (2006):1557-1576.

Zhu, Yan, Yan Li, and Weiquan Wang et al. "What leads to post-implementation success of ERP? An empirical study of the Chinese retail industry." International Journal of Information Management 30, 3 (2010):265-276.

Zubizarreta, Jon, Aguinaga, Iker, and Amundarain, Aiert. “A framework for augmented reality guidance in industry". International Journal of Advanced Manufacturing Technology 102, 9-12 (2019): 4095-4108. 